\title{
Review Article \\ Immunoregulation by Mesenchymal Stem Cells: Biological Aspects and Clinical Applications
}

\author{
Marta E. Castro-Manrreza and Juan J. Montesinos \\ Mesenchymal Stem Cells Laboratory, Oncology Research Unit, Oncology Hospital, National Medical Center, IMSS, \\ Avenue Cuauhtémoc 330 Col. Doctores, 06720 Mexico City, DF, Mexico
}

Correspondence should be addressed to Juan J. Montesinos; montesinosster@gmail.com

Received 5 September 2014; Revised 20 November 2014; Accepted 1 December 2014

Academic Editor: Marco Antonio Velasco-Velázquez

Copyright (C) 2015 M. E. Castro-Manrreza and J. J. Montesinos. This is an open access article distributed under the Creative Commons Attribution License, which permits unrestricted use, distribution, and reproduction in any medium, provided the original work is properly cited.

\begin{abstract}
Mesenchymal stem cells (MSCs) are multipotent cells capable of differentiation into mesenchymal lineages and that can be isolated from various tissues and easily cultivated in vitro. Currently, MSCs are of considerable interest because of the biological characteristics that confer high potential applicability in the clinical treatment of many diseases. Specifically, because of their high immunoregulatory capacity, MSCs are used as tools in cellular therapies for clinical protocols involving immune system alterations. In this review, we discuss the current knowledge about the capacity of MSCs for the immunoregulation of immunocompetent cells and emphasize the effects of MSCs on T cells, principal effectors of the immune response, and the immunosuppressive effects mediated by the secretion of soluble factors and membrane molecules. We also describe the mechanisms of MSC immunoregulatory modulation and the participation of MSCs as immune response regulators in several autoimmune diseases, and we emphasize the clinical application in graft versus host disease (GVHD).
\end{abstract}

\section{Introduction}

Mesenchymal stem cells (MSCs), also referred to as multipotent mesenchymal stromal cells, have been a focus of recent research, partially because they are an extraordinary model for investigating the biological mechanisms that allow a cellular population to generate diverse cell types and because they are a potential tool in cellular therapies for several clinical applications. MSCs can differentiate into mesenchymal lineages and secrete cytokines and growth factors with paracrine effects that favor the regeneration of damaged tissues $[1,2]$. Several studies have demonstrated that MSCs possess an immunoregulatory function in vitro and in vivo and that this property suggests clinical applications in the regulation of immunocompetent cell responses [2,3]. This review addresses current knowledge of the biological aspects involved in MSC immunoregulatory capacity and the clinical focus of these characteristics that allows these cells to be used in the treatment of several diseases with an immune component involved. This review culminates with a clinical description of the diseases treated with MSCs as a component of cell therapy procedures.

\section{Definition and Characteristics of MSCs}

MSCs are adult stem cells that are initially isolated from bone marrow (BM) [4] and can generate stromal BM components, such as adipocytes, reticular cells, and osteoblasts, whereas in conjunction with additional cellular components, MSCs maintain hematopoiesis [5]. MSCs proliferate in vitro as adherent, colony-forming cells with a high capacity for selfrenewal and proliferation $[4,5]$. Because there is no definite marker of MSCs, the International Society for Cellular Therapy has established minimum criteria that these in vitro cell populations must fulfill and certain characteristics to be considered MSCs. The cells must be positive for CD105, CD73, and CD90, express low levels of MHC-I, and be negative for MHC-II, CD11b, CD14, CD34, CD45, and CD31. Additionally, these cells must be capable of differentiation into osteoblasts, adipocytes, and chondroblasts in vitro $[5,6]$. 
MSCs have been isolated from multiple tissues: skeletal muscle, adipose tissue (AT), synovial membranes, dental pulp, periodontal ligaments, cervical tissue, menstrual blood, Wharton's jelly (WJ), umbilical cord (UC), umbilical cord blood (UCB), amniotic fluid, placenta (PL), and fetal tissues such as blood, liver, and BM [7-10]. In most cases, isolated MSCs are heterogeneous in proliferation and differentiation, although all express the characteristic MSC marker profile. MSCs cultivated in vitro possess three biological properties that qualify them for use in cellular therapy: (a) broad potential of differentiation, (b) secretion of trophic factors that favor tissue remodeling, and (c) immunoregulatory properties [2]. These traits make MSCs potential tools in many conditions. Furthermore, MSCs differentiate into different mesodermal lineages (adipocytes, chondrocytes, osteocytes, fibroblasts, and myocytes) [5]. Because of this potential for differentiation, MSCs were initially used in the treatment of imperfect osteogenesis [11] and myocardial damage [12]. The benefits observed in these initial cell therapy protocols were thought to be the result of osteogenic and myogenic differentiation [3]. The current understanding is that, in addition to diverse mesodermal differentiation capacity, MSC benefits arise primarily from the secretion of trophic factors and immunoregulatory capacity [1-3].

\section{Immunoregulatory Properties of MSCs}

Multiple studies have demonstrated the immunoregulatory properties of MSCs. MSCs profoundly affect immune response through their interactions with the cellular components of the innate (natural killer cells (NK)) and adaptive (dendritic cells (DCs), B lymphocytes, and T lymphocytes) immune system. MSC immunoregulation can occur through cellular contact and/or the secretion of diverse factors [1317]. Because of these properties, MSCs can prevent the inappropriate activation of $\mathrm{T}$ lymphocytes and generate a tolerogenic environment during wound repair or stop an immune response during healing, thus contributing to the maintenance of immune homeostasis [2, 3]. Below, we describe the immunoregulatory effects of MSCs on specific immune cells with special emphasis on the effect of MSCs on $\mathrm{T}$ lymphocytes because of their role as effector cells in many diseases with an immune component.

\subsection{Immunosuppressive Effects on Immunocompetent Cells}

3.1.1. T Lymphocytes. When lymphocytes are activated, they proliferate and differentiate to fulfill their effector functions. MSCs modulate each of these phases, thus influencing $\mathrm{T}$ lymphocyte immune response. The phases in which $\mathrm{T}$ cells are vulnerable to MSC immunoregulation, recognizing from a biological perspective that there are no obvious limits between phases, are described below.

(1) Activation. During activation, T lymphocytes express and secrete molecules characteristic of this phase, such as CD25, CD69, CD38, cytotoxic T lymphocyte antigen4 (CTLA-4), and human leukocyte antigen-DR (HLA-DR) and in addition the cytokines Interferon- $\gamma$ (IFN $\gamma)$, tumor necrosis factor $(\mathrm{TNF} \alpha)$, and IL-2, among others [18]. Currently, there are contradictory results regarding the effect of MSCs on T lymphocyte activation. Some studies have observed that BM-MSCs prevent the expression of the early activation markers CD25 and CD69 in T cells stimulated with phytohemagglutinin (PHA) $[19,20]$, whereas other studies describe no effect by BM-MSCs on the expression of these molecules $[16,21]$. Such contradictory results may be because of differences in the population of T lymphocytes studied. With this understanding, the activation of peripheral blood mononuclear cells (PBMC) with PHA in the presence of BMMSCs results in lower numbers of $\mathrm{CD}^{+}$and $\mathrm{CD}^{+}$that express CD25, CD38, and CD69 [20]. Employing the identical model, other authors have described a smaller proportion of cells expressing $\mathrm{CD}^{+} \mathrm{CD}^{+} 5^{+}$and $\mathrm{CD}^{+} \mathrm{CD} 38^{+}$[19]. Contradictory results report that the activation of $\mathrm{PBMC}$ with antibodies in the presence of BM-MSCs does not modify the expression of CD25 or CD 69 in $\mathrm{CD}^{+}$and $\mathrm{CD} 8^{+}$populations [21]. Similarly, no change was reported in the expression of CD25, CD69, or CTLA-4 in studies of populations enriched with $\mathrm{CD}^{+}$and $\mathrm{CD}^{+}$lymphocytes activated by alloantigens [16]. However, a recent study using populations enriched with $\mathrm{CD}^{+} \mathrm{T}$ lymphocytes activated with anti-CD2/CD3/CD28 in the presence of BM-MSCs showed an increase in the expression of $\mathrm{CD}^{2} 9^{+}$in $\mathrm{CD}^{+}$and $\mathrm{CD}^{+} \mathrm{T}$ lymphocyte populations [22]. These results emphasize the importance of the cellular context in MSC immunoregulation.

The effects of MSCs on the secretion of cytokines by activated T lymphocytes are also described by contradictory results. Some studies have demonstrated that the presence of MSCs diminishes $[14,21]$ or increases $[23,24]$ significantly the secretion of IFN $\gamma$ by activated T lymphocytes. Nonetheless, it has been described that the effects of MSCs on IFN $\gamma$ secretion depend on the source of the lymphocyte population studied [23]. In this study, the authors demonstrated that the activation of $\mathrm{CD}^{+}{ }^{+} \mathrm{T}$ lymphocytes with anti-CD3/CD28 in the presence of MSCs from adipose tissue resulted in an increase in IFN $\gamma$, which was an effect that was not observed when PBMC were activated with the identical stimulus. Our laboratory recently demonstrated that the activation of $\mathrm{CD}^{+}$ T cells with antibodies in the presence of BM-MSCs, UCBMSCs, and PL-MSCs also resulted in an increase in IFN $\gamma$ in cocultures [24]. This observed effect might be related to the generation of IFN $\gamma$-producing T regulatory cells (Tregs) [25].

(2) Proliferation. The effect of MSCs on the proliferation of $\mathrm{T}$ lymphocytes is independent of the activation method. The first studies to analyze the effects of BM-MSCs on the proliferation of $\mathrm{T}$ lymphocytes used irradiated MSCs that were cocultivated with alloantigen-stimulated PBMC. These studies reported that MSCs inhibited T-cell proliferation in a dose-dependent fashion $[13,16,17,19]$. However, in addition to inhibiting alloantigen-induced proliferation, MSCs can inhibit proliferation induced by polyclonal activators such as PHA $[14,26]$ or anti-CD3/CD28 [21, 23, 24]. The immunosuppressive effects of MSCs have been analyzed using total populations of PBMC and populations enriched in $\mathrm{CD}^{+}$, $\mathrm{CD} 4^{+}$, or $\mathrm{CD}^{+}$lymphocytes. Every case has demonstrated 
the capacity of MSCs to diminish proliferation $[13,16,17,19$, $21,23,24]$. Immunoregulation has been shown to be independent of the induction of apoptosis $[16,27]$ and is performed through mechanisms dependent and independent of cellular contact. Among the secreted factors identified are transforming growth factor beta $1\left(\mathrm{TGF}_{\beta 1}\right)$, hepatocyte growth factor (HGF), indoleamine-2,3-dioxygenase (IDO), prostaglandin E2 $\left(\mathrm{PGE}_{2}\right), \mathrm{IL}-10$, and HLA-G5 $[13,17,28]$, whereas programmed death-ligand 1 (PD-L1) and HLA-G1 are involved in contact-dependent mechanisms (Figure 1) [28-30]. Whether direct contact between MSCs and T lymphocytes is necessary for the inhibition of T-cell proliferation remains controversial. Some authors have suggested that MSCs act via an immunosuppressive mechanism independent of cell-to-cell contact $[31,32]$, whereas others have indicated that contact is required for efficient immunoregulation [24, 28-30, 33, 34]. However, the mechanism of MSC immunoregulation appears to depend on cellular populations, mode of activation, and the presence or absence of cell-to-cell contact $[23,32]$.

(3) Differentiation and Effector Function. Upon activation by the presence of pathogens or signs of damage, helper $\mathrm{T}$ cells $\mathrm{CD}^{+}$(Th0) differentiate into one of the following subtypes, depending on the T-cell microenvironment: Th1, Th2, Th17, or Tregs. Each population is characterized by the secretion of a set of cytokines whose function is essential to eliminate pathogens within the organism, resolve inflammation, and maintain immune homeostasis. Several studies have suggested that MSCs modulate the differentiation, function, and balance of these subpopulations and foster the development of an anti-inflammatory immune response (Figure 1) [14, $28,35,36]$. The activation of naïve $\mathrm{T}$ cells $\left(\mathrm{CD} 45 \mathrm{RA}^{+}\right)$in favorable conditions for the induction of Th1 or Th2 and in the presence of MSCs results in the inhibition of IFN $\gamma$ secretion by Th1 cells and the increase of IL- 4 secretion by Th2 cells [14]. Furthermore, MSCs inhibit the production of proinflammatory cytokines IL-17, IL-22, IFN $\gamma$, and $\mathrm{TNF} \alpha$ and the differentiation of naïve $\mathrm{CD} 4^{+}$lymphocytes to Th17. Additionally, MSCs promote the secretion of IL10 and the expression of the Foxp3 transcription factor, thus suggesting differentiation toward Tregs (Figure 1) [35]. Similarly, in a murine model, the presence of MSCs in the Th1 and Th17 differentiation processes favors differentiation to $\mathrm{CD}^{+} \mathrm{CD} 25^{+}$Foxp $^{+}$Tregs. This effect was not observed when MSCs were added to cultures of mature Th1 or Th17 populations [36]. These results indicate that MSCs affect the differentiation and function of inflammatory $\mathrm{T}$ lymphocyte populations in their capacity to produce proinflammatory cytokines and also in the induction of a Tregs phenotype.

Several studies have described the role of MSCs in the induction of distinct Tregs populations [14, 28, 37-40]. In an initial study analyzing the participation of BM-MSCs in the differentiation of Tregs populations, Maccario et al. observed that the presence of allogeneic and autologous MSCs, with respect to the responder T lymphocyte population in mixed lymphocyte culture (CML), induced a significant increase in the $\mathrm{CD} 4{ }^{+} \mathrm{CD} 25^{\text {bright }} \mathrm{T}$ lymphocyte population. However, only allogeneic MSCs favored an increase in $\mathrm{CD} 4^{+} \mathrm{CD} 25^{+} \mathrm{CTLA}-4^{+}$populations [37]. In the same year, a different study observed that PBMC activation by IL-2 in the presence of MSCs increased the proportion of $\mathrm{CD} 4^{+} \mathrm{CD} 25^{+} \mathrm{T}$ lymphocytes [14]. Subsequently, Prevosto et al. showed that PBMC in coculture with BM-MSCs generated a population of cells that could inhibit $\mathrm{T}$ lymphocyte proliferation induced by alloantigens or polyclonal activators (antiCD3 or PHA), and this effect required cell-to-cell contact. These Tregs populations could also be derived from $\mathrm{CD} 4^{+}$or $\mathrm{CD}^{+}$cells. The authors observed that the increase in Foxp3 mRNA expression occurred only in the Tregs populations derived from $\mathrm{CD} 4^{+}$lymphocytes [38]. MSCs can induce and maintain the function and phenotype of Tregs derived from $\mathrm{CD}^{+}, \mathrm{CD}^{+} \mathrm{CD}^{+} 5 \mathrm{RO}^{+}$, or $\mathrm{CD}^{+} \mathrm{CD} 45 \mathrm{RA}^{+} \mathrm{T}$ lymphocyte populations. Beginning with a $\mathrm{CD}^{+}$population, BM-MSCs

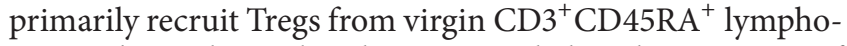
cytes. The authors also demonstrated that the presence of BM-MSCs maintained Foxp3 expression in Tregs [40]. MSCs from UC also have capacity to induce generation of Tregs [34].

Furthermore, MSCs can induce regulatory T type 1- (Tr1-) like cells characterized by IFN $\gamma$ and IL-10 secretion. Through an in vivo transplant-induced arteriosclerosis model (obstructed arteries), Jui et al. demonstrated that the local administration of BM-MSCs could prevent this pathology through a local increase in IFN $\gamma$ and IL-10 [41]. In a subsequent in vitro study, the identical laboratory demonstrated that BM-MSCs favored the generation of Tr1 lymphocytes with an IL- $10^{+} \mathrm{IFN} \gamma^{+} \mathrm{CD} 4^{+}$phenotype mediated by $\mathrm{PGE}_{2}$ and IDO (Figure 1) [25]. MSC participation in T lymphocyte subpopulation equilibrium has also been observed in human in vivo studies. Patients who have received MSCs for the treatment of GVHD show subsequent increases of $\mathrm{CD}_{4}^{+} \mathrm{CD} 25^{+} \mathrm{Foxp}^{+}$and $\mathrm{Tr} 1$ populations and decreases of $\mathrm{Th}^{+} 7^{+}$[42]. Similarly, the administration of MSCs to patients with systemic lupus erythematous induced an increase in $\mathrm{CD} 4^{+} \mathrm{CD} 25^{+} \mathrm{Foxp} 3^{+}$Tregs in the peripheral blood [43]. Increases in this Tregs population have also been observed in kidney transplant patients, which were transplanted with autologous MSCs [44].

3.1.2. Dendritic Cells. DCs are the most important antigen presenting cells in the body. These cells are derived from BM$\mathrm{CD} 34^{+}$cells in vivo and from monocytes stimulated with IL-4 and granulocyte macrophage colony-stimulating factor (GM-CSF) in vitro. The primary function of DCs is to process and present antigens to virgin and memory $\mathrm{T}$ cells, although they also interact with other immune components such as B lymphocytes and NK cells. The individual DCs must mature to initiate an appropriate immune response, and during the maturation process, DCs increase the membrane expression of MHC-II and T-cell costimulatory molecules CD80 and CD86. Immature DCs can not only activate $\mathrm{T}$ cells but also induce tolerance [45].

MSCs can affect the recruitment, maturation, and function of DCs. MSCs can significantly reduce monocyte differentiation into DCs, affecting the upregulation of CDla, CD40, CD80, CD86, and HLA-DR (Figure 2) [15, 37, 46-48]. This reduction is performed through the secretion of factors [15, 46] and is a reversible process because these monocytes then 


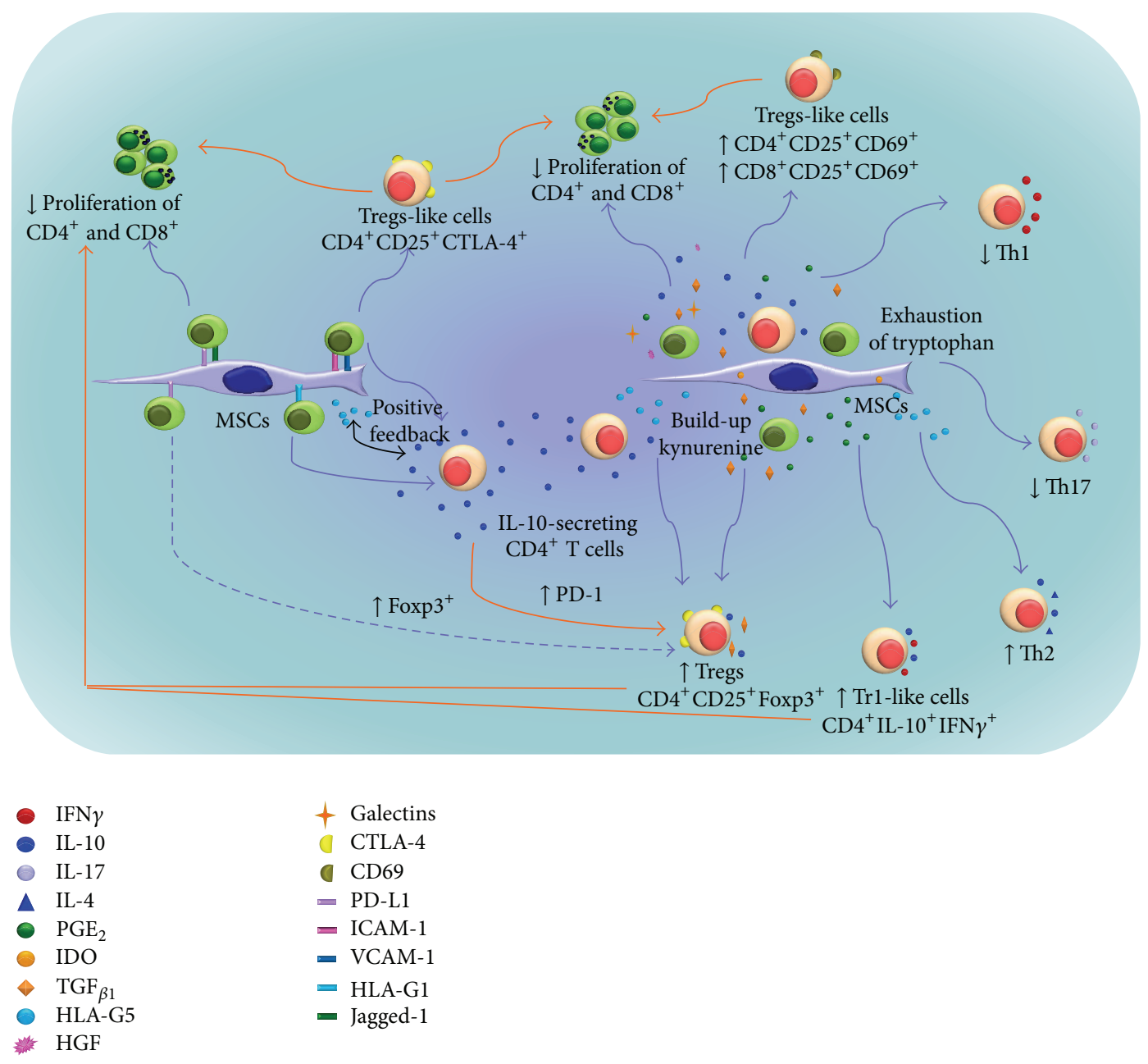

FIGURE 1: Immunoregulatory effect of MSCs on T lymphocytes. MSCs can induce the sustained expression of CTLA-4 and CD69 activation molecules on $\mathrm{T}$ cells, which have been related with generation of cells with immunoregulatory properties. Cell-to-cell contact seems to be required for the increase of CTLA-4 expression. Dependent and independent mechanisms of cellular contact are involved in the decrease of proliferation of $\mathrm{CD}^{+}$and $\mathrm{CD} 8^{+} \mathrm{T}$ cells and in generation of Foxp ${ }^{+}$Tregs by MSCs. Cytokines such as IL-10 can stimulate the expression and secretion of HLA-G5 by MSCs and in turn it stimulates the secretion of IL-10 in a positive feedback loop. The initial contact between MSCs and T lymphocytes seems to be required for initiation of the feedback loop. $\mathrm{PGE}_{2}$ secreted by MSCs is involved in generation of Trl cells. HLA-G5 supports differentiation of Th2 cells and IDO decrease differentiation of Th17.

differentiate normally at the removal of MSCs [15]. When immature DCs (iDCs) derived from monocytes-MSC cocultures were activated with lipopolysaccharide (LPS) to induce their final differentiation, they expressed lower levels of the maturation marker CD83 and costimulatory molecules CD80 and CD86. These results suggest that MSCs can maintain DCs in an immature state [15]. However, Spaggiari et al. showed that MSCs do not affect direct LPS-induced maturation of DCs in cocultures, because there was no change in CD80, CD83, and CD86 expression [47]. These results suggest that MSCs exert a strong inhibitory effect on the differentiation process from monocytes to iDCs but not on the LPS-induced maturation of iDCs to mature DCs (mDCs). In addition, mDCs cocultured with MSCs show a diminished expression of HLA-DR, CD1a, CD80, and CD86, thus suggesting that MSCs may push mDCs toward an immature state with a reduced stimulatory capacity (Figure 2) [47].
Additionally, MSCs affect the secretion of several cytokines that are key to DCs maturation. Aggarwal and Pittenger observed that MSCs inhibit the secretion of TNF $\alpha$ by DCs activated by LPS. The inhibition of TNF $\alpha$ secretion by DCs inhibits their maturation, migration to the lymph nodes, and their capacity to stimulate alloreactive $\mathrm{T}$ lymphocytes, because of the alteration in the expression of several receptors that are necessary to capture and process antigens [14]. MSCs also inhibit the DCs secretion of IL-12 $[15,47,48]$. The insufficient production of IL-12 is associated with the induction of T cell anergy and tolerance $[15,26,47]$. Human BM-MSCs that act through Notch can induce the differentiation of $\mathrm{CD} 34^{+}$hematopoietic progenitors into a population of regulatory DCs with specific properties: (1) the expression of high levels of IL-10 mRNA and low expression of IL-2 mRNA; (2) the capacity to inhibit alloreactive T-cell proliferation and function; and (3) the capacity to induce 


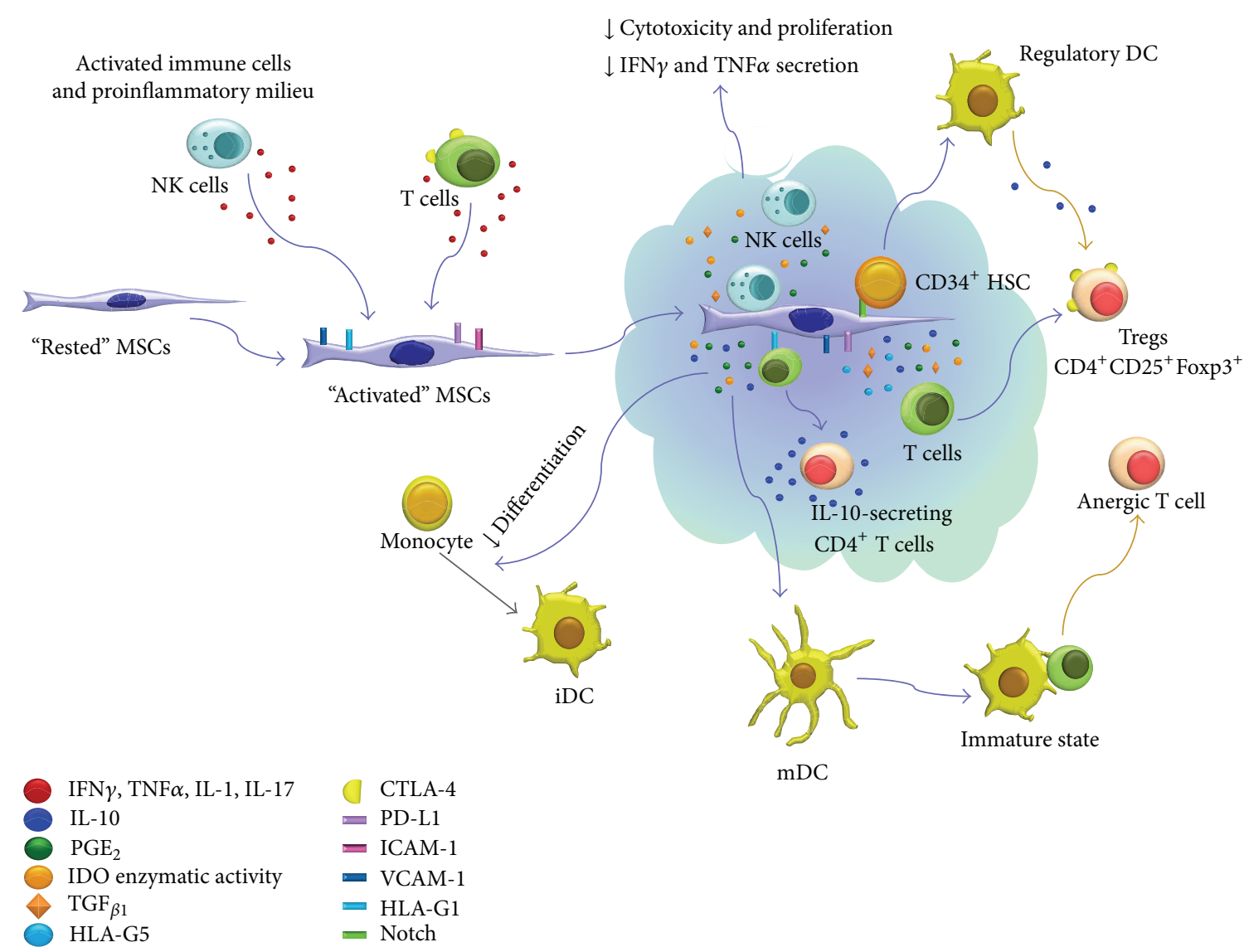

FIGURE 2: Immunoregulatory effects of MSCs on immune cells. Proinflammatory cytokines such as IFN $\gamma$ secreted by activated NK cells and T lymphocytes support MSCs-mediated immunoregulation and can increase or induce the production of immunosuppressive molecules. IDO, $\mathrm{PGE}_{2}, \mathrm{TGF}_{\beta 1}$, and membrane molecules are mainly involved in MSCs immunoregulation on NK cells. IDO, PGE 2 , and IL-10 are involved in the decrease of differentiation of monocytes into iDCs and may push mDCs toward an immature state, which results in T-cell anergy and inappropriate activation of T lymphocytes. MSCs induce the differentiation of $\mathrm{CD} 34^{+}$hematopoietic progenitors into a population of regulatory DCs, which in turn stimulate the generation of Foxp $3^{+}$Tregs.

Tregs differentiation characterized by expression of Foxp3 and $\mathrm{TGF}_{\beta 1}$ mRNA (Figure 2) [49].

3.1.3. NK Cells. NK cells are important in innate immunity and participate in the body's defenses against infections and cancer. NK cells perform their effector function through the secretion of cytokines, such as IFN $\gamma, \mathrm{TNF}_{\beta}$, and GMCSF, and possess cytotoxic activity both spontaneous and antibody-dependent [50]. NK function is regulated by the equilibrium of signals transmitted by activator and inhibitor receptors that interact with specific HLA molecules on target cells. Thus, HLA-class I negative or HLA-class I-mismatched cells represent potential targets of NK cells [27, 50]. MSCs affect the phenotype, proliferation, cytotoxic potential, and cytokine secretion of NK cells (Figure 2). When activated by IL-2, NK cells secrete IFN $\gamma$, but when activated in the presence of MSCs, IFN $\gamma$ secretion significantly decreases [14]. Furthermore, NK cells activated by IL- 2 and alloantigens in the presence of MSCs show diminished proliferation and lytic activity $[16,51]$. IL-15 is another cytokine that promotes the proliferation, survival, and effector function of NK cells, but through factor secretion, MSCs can inhibit IL-15 induced proliferation [27]. However, MSCs and NK cell contact are necessary to inhibit NK cytotoxicity in tumor cell lineages [27].

3.1.4. B Lymphocytes. B lymphocytes are involved in the adaptive immune response. These cells are responsible for humoral immunity and are specialized for antibody production [52]. Few studies have analyzed the effects of MSCs on B lymphocytes; however, MSCs diminish B-cell proliferation by cell cycle arrest in the G0/G1 phase and not by inducing apoptosis [53]. A recent study demonstrated that effect of MSC on B lymphocytes proliferation with CpG is not direct and requires presence of $\mathrm{CD}^{+} \mathrm{T}$ cells [54]. MSCs can also affect B-cell differentiation because IgM, IgG, and IgA production are diminished [53-56]. Furthermore, MSCs modify the chemotactic properties of B lymphocytes, because expression changes in their chemokine receptors including CXCR4, CXCR5, and CCR7 were induced by MSCs [53]. 


\subsection{Soluble Factors Involved in MSC Immunoregulation}

3.2.1. $T G F_{\beta 1}$ and HGF. The first molecules described in the MSC-mediated immunoregulation of alloantigen-activated $\mathrm{T}$ lymphocytes were $\mathrm{TGF}_{\beta 1}$ and HGF. Both cytokines can independently diminish alloantigen-activated T lymphocyte proliferation, although proliferation can be partially reestablished through blocking with antibodies [20, 31]. MSCs constitutively express $\mathrm{TGF}_{\beta 1}$ and HGF, which appear to act synergistically [17]. $\mathrm{TGF}_{\beta 1}$ is involved in the MSCmediated generation of $\mathrm{CD}^{+} \mathrm{CD} 25^{+} \mathrm{Foxp}^{+}$Tregs (Figure 1) [39] and in the decreased proliferation of NK cells [27]. These results suggest that $\mathrm{TGF}_{\beta 1}$ and HGF, in addition to other mechanisms, participate in the suppression of MSC-mediated proliferation in mixed lymphocyte culture (MLC).

3.2.2. Indoleamine-2,3-dioxygenase. IDO is an enzyme that catalyzes the conversion of the amino acid tryptophan to kynurenine. The inhibition of $\mathrm{T}$ lymphocyte proliferation is because of the exhaustion of tryptophan or the build-up of kynurenine [57]. There is experimental evidence supporting both hypotheses. Thus, the addition of exogenous tryptophan has been shown to reestablish alloantigen-activated T-cell proliferation in the presence of MSCs [13]. Similarly, the addition of kynurenine to MLC inhibits proliferation without MSCs, however such inhibition is lower when compared with that observed in cultures in the presence of MSCs [17]. The use of competitive inhibitors of IDO reduces MSC immunosuppressive effects on alloantigen-activated $\mathrm{CD} 4^{+}$ T lymphocytes [16]. Notably, the reestablished proliferation does not reach the levels observed in MLC without MSCs, thus suggesting the presence and participation of additional mechanisms [13]. The exhaustion of tryptophan by IDO participates in the inhibition of Th17 differentiation; however, this mechanism and the build-up of kynurenine are involved in the IDO generation of Foxp $3^{+}$Tregs [57]. Furthermore, IDO is involved in the decrease of proliferation and cytotoxic activity of NK cells activated by IL-2 in the presence of MSCs [51] and also in the inhibition of maturation and functional activity of DCs (Figure 2) [45].

3.2.3. Prostaglandin $E_{2}$. $\mathrm{PGE}_{2}$ also plays a role in MSC-mediated immunoregulation. $\mathrm{PGE}_{2}$ is a lipid mediator derived from the conversion of arachidonic acid to prostaglandin through COX1 and COX2 enzyme action [58]. These enzymes, with $\mathrm{PGE}_{2}$, are constitutively expressed by MSCs, although their expression increases in an inflammatory environment $[14,17] . \mathrm{PGE}_{2}$ has been shown to diminish proliferation, stimulate the secretion of IL- 4 and IL-10, and promote $\mathrm{CD}^{+} \mathrm{CD} 25^{+} \mathrm{Foxp}^{+}$and $\mathrm{IL}-10^{+} \mathrm{IFN} \gamma^{+} \mathrm{CD} 4^{+}$Tregs differentiation (Figure 1) $[25,59]$. Several studies have shown that $\mathrm{PGE}_{2}$ is a MSC effector molecule; synthesis can be blocked with indomethacin or NS-398, and activated T-cell proliferation increases, but not similar to levels observed of T-cell proliferation in absence of MSCs $[14,17,32,60]$. PGE $_{2}$ is involved in the decrease of differentiation of monocytes into DCs [47] and the decrease of proliferation and cytotoxic activity of NK cells activated by IL-2 in the presence of MSCs (Figure 2) [51].
3.2.4. IL-10. It has been reported that IL-10 is expressed by human [17] and murine [61] MSCs and that TLR3 ligand increases the IL-10 secretion by human MSCs [62]. However, other authors have showed that murine $[16,63]$ and human MSCs do not express IL-10 [64]. Despite these conflicting results, some studies have reported a high concentration of IL-10 in the supernatant from cocultures of fetal or adult MSCs and immune cells and their participation in the immunosuppression by MSCs in such cocultures have been well demonstrated [38]. In that regard, some authors have showed that cell-to-cell contact between BM-MSCs and T cells appears vital in the concentration increase of IL-10 in the supernatant $[24,38,64]$. Participation of IL-10 in BM-MSCmediated immunoregulation and in Tregs generation has been demonstrated through the use of antibodies $[17,20]$. IL10 downregulates Th1 cytokine expression and can stimulate the expression and secretion of HLA-G5, which is another important molecule in MCS-mediated immunoregulation [28]. A recent study reported an increase in immunosuppressive capacity of $\mathrm{CD} 4^{+} \mathrm{CD} 25^{+}$Tregs cocultured with BMMSCs, which is due to a high expression of PD-1 on Tregs stimulated by IL-10 present in the coculture supernatant (Figure 1) [65]. Furthermore, IL-10 is also involved in the decrease of maturation and function of DCs, inhibiting the ability of DCs to produce IL-12 (Figure 2) [61].

3.2.5. HLA-G5. HLA-G molecules are nonclassic HLA molecules characterized by a limited allelic polymorphism and a tissue-specific expression pattern. There are membranebound isoforms (HLA-G1, G2, G3, and G4) and soluble isoforms (HLA-G5, G6, and G7) [66]. BM-MSCs express the membrane-bound isoform HLA-G1 and the soluble isoform HLA-G5 [28, 30]; expression of both molecules is promoted by IL-10 [28]. Similarly, HLA-G5 stimulates the secretion of IL-10 in a positive feedback loop. The simultaneous use of antibodies against both molecules nearly reestablishes proliferation of alloantigen-activated $\mathrm{PBMC}$ in the presence of MSCs [28, 67]. Direct contact between MSCs and T cells is required to establish the positive feedback loop and subsequent generation of an immunosuppressive environment, which is further exacerbated by the generation of the $\mathrm{CD} 4^{+} \mathrm{CD} 25^{+}$Foxp $^{+}$Tregs induced by both molecules (Figure 1) [28].

3.2.6. Galectins. Galectins are a family of proteins that bind specifically to $\beta$-galactoside. Eleven of the 15 galectins are distributed in lymphoid and nonlymphoid tissues. Galectins participate in the regulation of cellular homeostasis in both adaptive and innate immunity as immunostimulators or immunosuppressors [68]. Several galectins have been implicated in MSC-mediated immunoregulation as is described below. Galectin-1 mRNA and protein are constitutively expressed and released into culture medium by MSCs [69]. The silencing of Galectin-1 expression using siRNA [70] or antibodies [71] reestablishes proliferation of PBMC activated by mitogens or alloantigen, thus indicating that Galectin1 participates in MSC immunoregulation. Similarly, MSCs express Galectin-3, a molecule known to regulate T-cell proliferation, adhesion, and migration [68]. The inhibition of 
Galectin-3 expression in MSCs with siRNA reduces immunosuppressive capacity on alloantigen-activated T lymphocytes [72]. Ungerer et al. recently demonstrated that Galectin-9 also participates in MSC-mediated immunoregulation. The authors observed that MSCs express higher levels of Galectin9 in an inflammatory environment, and through the use of antibodies, the authors described the participation of Galectin-9 in the MSC-mediated proliferation reduction of stimulated T and B lymphocytes $[73,74]$.

3.3. Membrane Molecules Involved in MSC-Mediated Immunoregulation. The following membrane molecules participate in MSC-mediated immunoregulation: the PD-1/PD-L1 pathway, HLA-G1, Jagged-1, and adhesion molecules, such as intercellular adhesion molecule 1 (ICMA-I) and vascular cell adhesion molecule 1 (VCAM-I) (Figure 1). PD-L1 (B7$\mathrm{H} 1 / \mathrm{CD} 274)$ and its receptor (PD-1/CD279) are components of a $\mathrm{T}$ lymphocyte costimulatory pathway that releases inhibitory and regulatory signals upon activation. The pathway is involved in tolerogenesis and immune response termination to avoid tissue damage [75]. The PD-1/PD-L1 pathway is activated in the event of a persistent antigenic stimulus, as occurs with self-antigens, chronic viral infection, or tumors. The activation of this pathway prevents autoimmunity and directly contributes to the immunosuppressive microenvironment observed in tumors through T-lymphocyte regulation [75]. In murine models [29] and human MSC from PL [76], UC [34], and BM [34, 65, 77], it has been observed that IFN $\gamma$ induce an increase of PD-L1 expression and has been demonstrated the participation of PD-L1 in MSCmediated immunosuppression of $\mathrm{T}$ cell proliferation through the use of monoclonal antibodies $[29,75,76]$. Future studies will be necessary to determine the participation of PD-L1 expressed on MSCs in the expression of Foxp-3 in T cells. Interestingly, an increase in the expression of $\mathrm{PD}-\mathrm{L} 1$ receptor (PD-1) has been observed in activated $\mathrm{CD} 4{ }^{+} \mathrm{CD} 25^{+}$Tregs cocultured with BM-MSCs, which is associated with a high immunosuppressive capacity. The same increase in PD-1 was observed in $\mathrm{CD} 4{ }^{+} \mathrm{CD} 25^{-} \mathrm{T}$ cells, but in contrast with Tregs, it is associated with apoptosis $[65,77]$.

HLA-G1 is similarly important in MSC-mediated immunoregulation. Giuliani et al. [30] demonstrated that the reduced proliferation in anti-CD3/CD28-activated T lymphocytes in the presence of MSCs derived from BM or fetal liver was primarily driven by cell-to-cell contact and that MSCs expressed higher levels of HLA-G1 in coculture. Furthermore, the use of antibodies specific to this molecule nearly reestablished Tlymphocyte proliferation and reduced concentration of IL-10 in cocultures, which shows the relevance of cell-to-cell contact [30]. Similar studies have reported the importance of cell-to-cell contact between MSCs and $\mathrm{T}$ cells in such mechanisms $[24,38,64]$. It appears that cell-to-cell contact in cocultures promotes expansion of $\mathrm{CD}^{+} \mathrm{T}$ cells which produce IL-10 and increase the expression of CD210 (IL-10 receptor, subunit A) on $\mathrm{CD}^{+} \mathrm{T}$ cells but not on $\mathrm{CD}^{+} \mathrm{T}$ cells and MSCs [64]. These results suggest that through cell-to-cell contact between MSCs and $\mathrm{T}$ cells a population of $\mathrm{T}$ cells whose secreted products contribute to the immunoregulatory environment generated by MSCs is formed (Figure 1).

The participation of the adhesion molecules ICAMI and VCAM-I has been demonstrated using antibodies against both adhesion molecules, which are expressed by MSCs during T-cell immunoregulation. When ICAM-I and VCAM-I were blocked in a mouse model, anti-CD3activated splenocyte proliferation was partially reestablished [78]. Additionally, the expression of ICAM-I and VCAMI increased when MSCs were exposed to IFN $\gamma$ [35]. These results suggest that MSCs increase the capacity to recruit inflammatory T-lymphocyte populations and modulate its own function toward a regulatory phenotype as was demonstrated in the Th17 population [35]. Furthermore, adhesion molecules could be involved in T-cells immunoregulation through induction of CTLA-4 expression on T cells, which has been previously demonstrated [79, 80]. Our laboratory recently demonstrated that cell-to-cell contact between activated $\mathrm{CD}^{+}$lymphocytes and MSCs from BM or UCB increased the expression of CTLA-4 (Figure 1) [24].

Through different mechanisms CTLA-4 is a negative regulator of immune response. It has been demonstrated that interaction between CTLA-4 with CD80/B7-1 and CD86/B72 expressed in DC induces IDO upregulation by DC [57]. It is likely that a similar mechanism is present in CD $4^{+}$CTLA$4^{\text {high }} \mathrm{T}$ cells generated in cocultures with MSC $[24,37,38]$. This idea is supported by several evidences; activated T cells express CD80 and CD86, in particular the presence of MSC induces increased expression of CD86 on $\mathrm{CD}^{+} \mathrm{T}$ cells [81], and it has been shown that the interaction of these molecules with CTLA-4 induced IDO expression in CD $4^{+} \mathrm{T}$ cells [82].

The cell-to-cell contact between MSCs and CD $3^{+} \mathrm{T}$ cells is important in the immunosuppresion of B cells by MSCs [54]. This evidence suggest that inhibition of B-cell proliferation observed in cocultures with MSC is dependent of soluble factors produced during cell-to-cell contact between $\mathrm{T}$ cells and MSCs. Another molecule involved in the inhibition of T lymphocyte proliferation is Jagged-1, a Notch ligand [83]. Because Jagged-1 is expressed in MSCs suggests that Notch signaling is involved in MSC immunosuppressive functions. Liotta et al. showed that when Jagged-1 was blocked by antibodies, the MSCs inhibitory effects were decreased on a population of alloantigen-activated $\mathrm{CD} 4^{+}$lymphocytes [84].

\section{The Modulation of MSC Immunoregulatory Properties}

Many studies suggest that MSCs and immune cells have established two-way regulatory mechanisms; thus, the activation of MSC immunoregulatory properties requires the presence of derived proinflammatory cytokines from immune cells. Similarly, as a result of this activation, factors secreted by MSCs also regulate immune response.

4.1. MSC Activation Requires an Inflammatory Environment. MSCs must be "activated" to efficiently perform their immunoregulatory role [2]. Broad evidence demonstrates that 
this "activation" requires the presence of proinflammatory cytokines derived from $\mathrm{T}$ lymphocytes, macrophages, and NK cells, thus indicating that there are bidirectional regulatory mechanisms between MSCs and immune cells. Cytokines, such as IFN $\gamma$, are necessary in this process, either alone or in combination with TNF $\alpha$, IL- $1 \alpha$, IL- $1 \beta$, or IL-17 $[14,17,85]$ (Figure 2). The importance of an inflammatory environment for MSC immunosuppressive capacity has been shown both in vitro and in vivo. The initial experiments indicated that when exposed to IFN $\gamma$, MSCs induce the expression of IDO [13, 17] and PD-L1 [34] and increase the secretion of $\mathrm{PGE}_{2}[14,60]$. Similarly, the conditioned medium of MSC- and IL-15-activated NK cell cocultures can inhibit NK-cell proliferation, which indicates that this coculture activates MSC immunoregulatory properties [27]. Other studies have shown that NK cells can produce IFN $\gamma$ when they interact with MSCs (autologous or allogeneic), and MSC exposure to IFN $\gamma$ increases the expression of HLA-I in MSCs, which reduces the secretion of cytokines and cytotoxic activity of NK cells [51] (Figure 2). This evidence suggests that bidirectional regulatory mechanisms drive the interaction between MSCs and NK cells. MSCs express NK receptor ligands, such as PVR, Nectin-2 (NAM-1 ligands), and ULPBs and MICA (NKG2D ligands). Because of these receptorligand profiles, it is likely that the interaction of NK cells and MSCs (autologous or allogeneic) results in IFN production by NK cells, whereas this exposure of MSCs to IFN $\gamma$ increases HLA-1 expression in MSCs and other immunoregulatory molecules, thereby reducing the secretion of cytokines and NK cytotoxic activity [51]. In addition to the abovementioned cytokines, a recent study reported that IL-17 together with IFN $\gamma$ and TNF $\alpha$ increased inhibition of T-cell proliferation mediated by MSCs, apparently through a synergic effect of the three cytokines, leading to a high expression of inducible nitric oxide synthase (iNOS) [85].

Ankrum et al. recently suggested that MSCs are not fully immunoprivileged because of their capacity to activate cells of the immune system (NK cells, macrophages, etc.) and may even be rejected by such immune cells [86]. Thus, resting MSCs are immunogenic and able to promote the secretion of inflammatory cytokines, which in turn induce MSC to express and secret distinct immunoregulatory molecules, allowing them to evade the immune response. In this regard, it has been demonstrated that naive MSCs or primed previously with INF $\gamma$ plus $\mathrm{TNF} \alpha$ are able to decrease T-cells proliferation. However, naive MSCs induce the secretion of INF $\gamma$ and IL- 2 by activated T cells at two days of coculture and this is a cellular event prior to inhibition of proliferation. The authors suggested that unprimed MSC transiently induce proinflammatory cytokines secretion, which promote the increase of their immunoregulatory capacity [87].

In vivo studies in mouse models suggest that MSCs are effective in the treatment, but not prevention of GVHD. The highest survival rates were obtained when MSCs were administered when serum IFN $\gamma$ concentrations peaked. The injection of MSCs preactivated with high concentrations of IFN $\gamma$ was effective in GVHD prevention and resulted in $100 \%$ survival. However, the injection of MSCs with low concentrations of IFN $\gamma$ did not increase survival [88].
Similar results were observed in clinical trials. The administration of MSCs to patients with steroid refractory GVHD significantly improved patient outcomes [89, 90]. However, when MSCs were administered simultaneously with hematopoietic stem cells (HSC), there was no change in grade II/IV GVHD incidence and a high incidence of relapse [91].

4.2. MSCs and Toll-Like Receptors. Toll-like receptors (TLRs) are expressed by many immune cells, and their principal function is to detect pathogens. The activation of TLRs is essential to initiate an innate immune response and supports the adaptive immune response. Ten TLR types have been identified in humans and each recognize specific molecular patterns associated with bacterial, viral, or fungal pathogens. The signaling pathway common to all TLRs is the activation of NF- $\kappa \beta$, which controls the expression of several inflammatory cytokines and the expression of maturation markers [92]. Different TLRs are involved in autoimmune diseases, chronic inflammation, and infections [93].

MSCs express TLR-2, 3, 4, 5, 6, 7, and 9, which are all functional (except TLR-9) because its activation results in receptor internalization and the activation of the NF$\kappa \beta$, MAPK, and AKT pathways $[62,84,94]$. The initial analyses of TLR participation in MSC-mediated immunoregulation described contradictory results. An in vitro population enriched with alloantigen-activated $\mathrm{CD} 4^{+}$lymphocytes cultured in the presence of poly(I:C) or LPS-treated MSCs, activated TLR- 3 and TLR- 4 in the MSCs, thus inhibiting their immunosuppressive capacity. This effect may be because of the reduced expression of Jagged-1 in MSCs [84]. Contradictory results by Opitz et al. showed an augmentation in immunosuppressive capacity after TLR-3 and TLR-4 activation in MSCs, which continued to inhibit T-cell proliferation, even in low MSC: T cells ratio in cocultures [94]. These contradictory results can be explained with additional evidence from Tomchuck et al. who observed that TLR3 activation in MSCs supports the activation of the antiinflammatory cytokines IL-10 and IL-12, whereas TLR-4 activation supports the secretion of proinflammatory cytokines [62]. These results were corroborated by Waterman et al. who reported that TLR-3 supported MSC immunosuppressive effects, whereas TLR-4 supported proinflammatory effects. These authors proposed that MSCs could be polarized to one of two phenotypes: proinflammatory or anti-inflammatory. Each MSC population may possess unique characteristics and differ in their secretion of cytokines, differentiation capacity, extracellular matrix deposits, $\mathrm{TGF}_{\beta 1}$-signaling pathways, and expression of Jagged, IDO, and $\mathrm{PGE}_{2}$ [95]. However, the TLR participation in the immunoregulation by MSCs remains controversial. A recent study demonstrated the secretion of proinflammatory cytokines by MSCs upon activation of TLR3 or TLR-4 [96].

\section{Immunoregulation in Alternative Sources of BM-MSCs}

Currently most studies on the biology of MSCs have used BM-derived MSCs. Similarly, most literature describing the 
TABLE 1: Description of the molecules involved in immunoregulation mechanisms by MSCs from different sources.

\begin{tabular}{|c|c|c|}
\hline Sources of MSC & $\begin{array}{l}\text { Molecules involved in MSC } \\
\text { immunosuppression }\end{array}$ & Reference \\
\hline Bone marrow & $\begin{array}{l}\text { IDO, } \text { TGF }_{\beta 1}, \text { HGF, IL-10, } \\
\text { HLA-G, PDL-1, PGE }\end{array}$ & $\begin{array}{l}{[8,13,14,16,17,} \\
20,28,31,32,34, \\
38,45,46]\end{array}$ \\
\hline Placenta & $\begin{array}{l}\text { IDO, TGF } \\
\text { PDL-1 } \\
\text { PD-10, HLA-G, }\end{array}$ & {$[24,67,76,97,98]$} \\
\hline $\begin{array}{l}\text { Umbilical cord } \\
\text { blood }\end{array}$ & $\begin{array}{l}\text { IDO, } \text { TGF }_{\beta 1}, \text { HGF, HLA-G, } \\
\text { PDL-1, PGE }\end{array}$ & {$[24,60,98]$} \\
\hline Umbilical cord & $\begin{array}{l}\text { IDO, } \text { GFF }_{\beta 1}, \text { HGF, IL-10, } \\
\text { HLA-G, PDL-1, PGE } \\
\end{array}$ & {$[34,98,100,101]$} \\
\hline Adipose tissue & $\begin{array}{l}\text { IDO, TGF } \\
\text { PGE }_{2}, \text { HGF, IL-10, }\end{array}$ & {$[8,101]$} \\
\hline Wharton's jelly & $\begin{array}{l}\text { IDO, TGF } \beta_{\beta 1}, \text { HGF, IL-10, } \\
\text { HLA-G, } \text { PGE }_{2}\end{array}$ & {$[8,98,101,104]$} \\
\hline
\end{tabular}

molecules that participate in immunoregulatory mechanisms are specific to BM-MSCs $[8,13,14,16,17,20,28,31,32,38]$. Few studies have used other sources such as PL [24, 76, 9799], UCB [24, 60, 98], UC [34, 98, 100-102], AT [8, 99, 101103], and WJ $[8,98,99,101,104]$ (Table 1). Immune cell studies that have used MSCs derived from PL, AT, UCB, WJ, placental villi, amnion, and chorion have focused principally on T lymphocytes, one of the most studied cell types in MSC immunoregulation [8, 24, 76, 97, 101-103, 105-111] (Table 2). The search for alternative sources is particularly important not only because obtaining BM is expensive and invasive, but also because of reports that MSC differentiation capacity diminishes as the individual ages $[112,113]$.

Some reports have compared the immunoregulatory properties of MSCs from different sources to determine which is the most viable for BM replacement. In this regard, our research group has demonstrated that MSCs from BM and UCB, have identical immunoregulatory capacity [24]. However we have shown, in the same way as other groups, that in contrast to BM-MSCs, PL-derived MSCs have a lower capacity $[24,107]$. In fact, results relating to PL are contradictory between groups $[76,97,99,108]$. In this regard, results of a preclinical study for treatment of 9 patients with grades III-IV acute GVHD with PL-MSCs showed complete and partial recovery in two and four patients, respectively. No recovery was observed in two patients and one patient presented with convulsions [114]. The inconsistency of the results observed in clinical application of PL-MSCs could be related to the inconsistent results obtained in vitro by various groups. A different study comparing UC-, UCB-, PL-, and WJ-derived MSCs observed differences in the capacity to express HLA-G or $\mathrm{TGF}_{\beta 1}$ after activation with IFN $\gamma$. There were no differences observed in IDO secretion [98]. Screening for immunosuppressive factors in WJ- and BM-MSCs activated with IFN $\gamma$ or TNF $\alpha$ has indicated differences in the postactivation secretion of IDO, HGF, and $\mathrm{PGE}_{2}$, which may influence immunoregulatory properties [104]. It is important to pursue comparative studies to determine whether MSCs from alternative sources operate with the identical immunoregulatory mechanisms as BMMSCs, which are used in cellular therapy. These studies will be vital in determining alternative sources of MSCs for their potential implementation at the clinical level.

\section{MSCs and Clinical Applications}

The use of stem cells to replace cells and tissues damaged by congenital or degenerative disease or trauma is called stem cell therapy. In such procedures, cells are administered to patients through the blood or directly to the damaged tissue. The use of stem cells in cellular therapy is a current topic of debate. We previously outlined that MSCs have three biological properties that make them potential candidates for this use: high differentiation potential, trophic factor secretion, and immunoregulatory capacity. MSCs are potentially applicable to many diseases, such as GVHD, autoimmune diseases and bone, cartilage, and cardiovascular diseases. The beneficial effects of MSCs administration regarding several of the aforementioned diseases have been analyzed in animal models and phases I, II, and III clinical studies have been initiated $[115,116]$. In the following sections, we focus on the use of MSCs in the treatment of immune-associated diseases with special emphasis on the treatment of GVHD.

6.1. Graft versus Host Disease. Because of their immunoregulatory properties, BM-MSCs have been applied principally in HSC transplants because MSCs are capable of treating and preventing GVHD [89, 117-119]. After HSC transplant, GVHD presents when donor $\mathrm{T}$ lymphocytes recognize patient HLA molecules (alloantigen) as nonself and mount an immune response (allogeneic immune response). GVHD can be acute or chronic depending on the time of onset and intensity of tissue damage. Acute GVHD (aGVHD) appears within the first 100 days of the transplant, whereas chronic GVHD (cGVHD) has a later onset. Although the exact pathophysiology is unknown, three phases are believed to describe aGVHD onset: (1) the activation of host antigen presenting cells (APCs) by the transplant conditioning regimen (radiotherapy and/or chemotherapy); (2) the activation of T lymphocytes, which proliferate and differentiate in response to histoincompatible antigens presented by APCs; and (3) a cellular effector and inflammatory phase. The final phase is a combined effect of different sectors of the immune system (cytotoxic T lymphocytes and NK cells) and inflammatory cytokines (IFN $\gamma, \mathrm{TNF} \alpha$, IL-1, etc.), which together promote inflammation and tissue damage in various organs and can cause death [120].

The first clinical trial evaluating the safety and effectiveness of MSCs in the treatment of GVHD was performed by Frassoni et al. who observed that the coinfusion of HSC and nonirradiated MSCs from the identical donor reduced the incidence and severity of GVDH in recipients of an allograft from an HLA-identical sibling [121]. Subsequently, Le Blanc et al. reported the case of a 9-year-old boy with steroid refractory aGVHD grade IV who was treated with haploidentical MSCs from his mother. The child improved significantly on the 4 th day after infusion. Approximately 70 days after treatment, the child had renewed symptoms of 


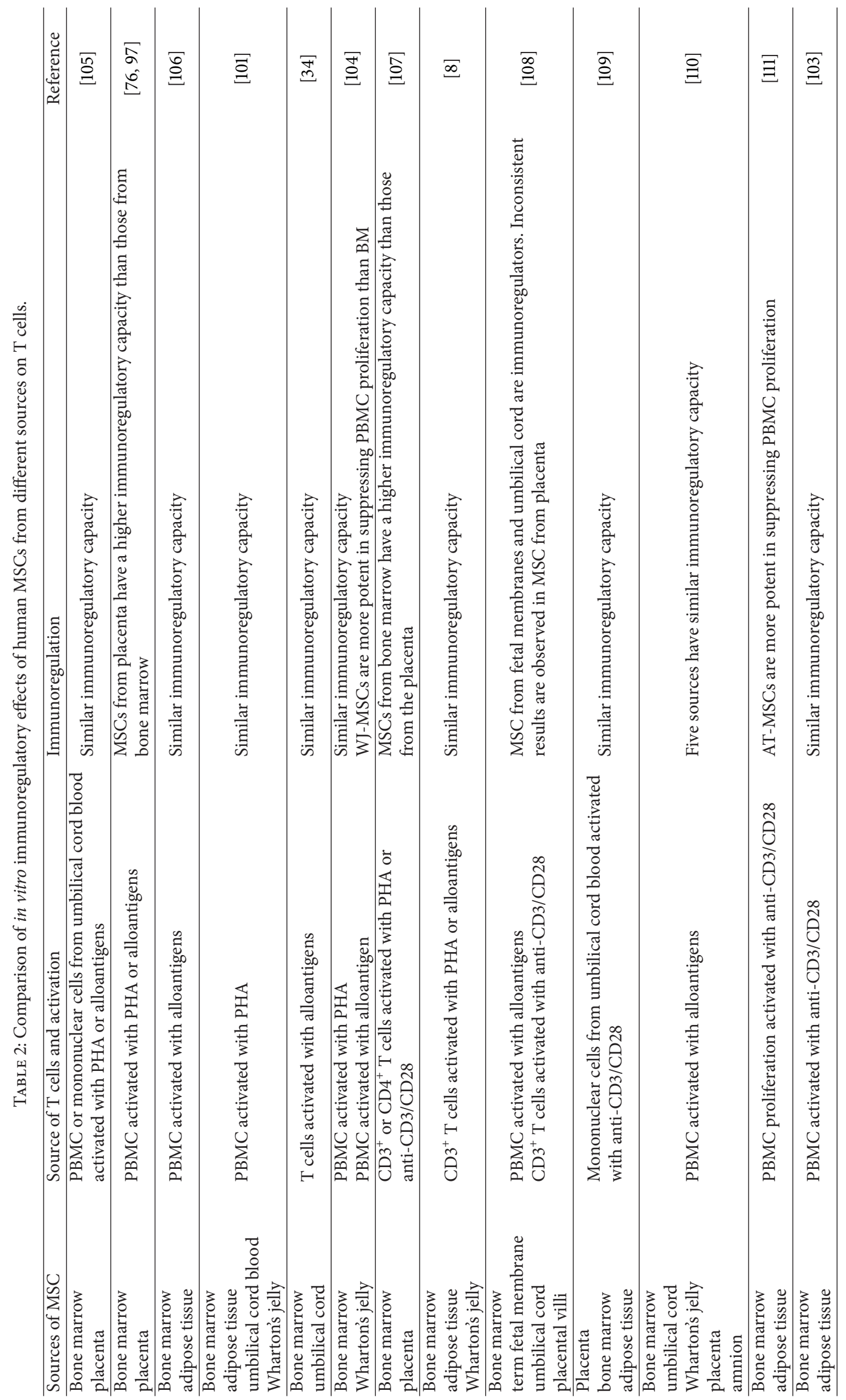




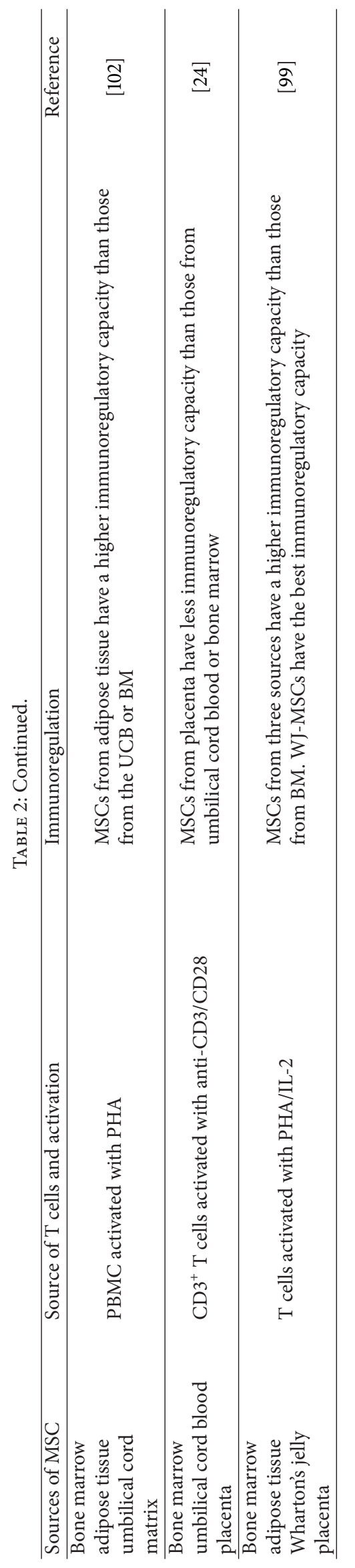


diarrhea and high levels of bilirubin. The administration of a second dose of MSCs significantly improved the patient's condition, and he remained stable throughout the following 100 days [121]. After this case, the identical group reported another study with the administration of MSCs to 8 steroids refractory GVHD grades III-IV patients. No toxic effects were observed, and survival was significantly improved compared to the control [89]. In a multicenter phase II study of 55 steroid refractory GVHD patients. A response was observed in 39 patients treated with MSCs, of which 30 recovered completely and 9 partially recovered. Survival was significantly improved in patients experiencing full recovery, and the mortality rate was significantly lower than that generally associated with the transplant. The authors suggest that the effect of the MSCs was independent of the donor because MSCs of HLA-identical, haploidentical, and incompatible siblings had similar results [90].

Other studies on the use of MSCs have reported less encouraging results. von Bonin et al. treated 13 patients with steroid-refractory aGVHD with different doses of MSCs (1-5 applications) from unrelated donors that had been expanded in medium with platelet lysate. Only 5 patients responded to treatment and only 4 were alive after 257 days of treatment [122]. Similarly, Müller et al. reported the treatment of 5 children with acute or cGVHD. MSCs doses were increased in accordance with cell availability from $0.4 \times 10^{6}$ to $3.0 \times$ $10^{6} / \mathrm{kg}$. Only one patient responded to this treatment [123]. In addition, it has been suggested that the cotransplant of HSC and BM-MSCs may prevent GVHD, but there is a high rate of relapse [91]. However, a clinical trial with 37 children treated with multiple doses of BM-MSCs for steroidrefractory grades III-IV aGVHD reported complete response in 24 children and partial response in 8 children [124]. The contradictory results may be because of differences in the method of MSC expansion, the number of cells administered, number of doses given, diagnosis of the recipient (chronic or aGVHD), stage of GVHD development, and administration of MSCs, among others. In attempts to eliminate some these variables, clinical studies have been performed with a universal BM-MSC preparation, such as Prochymal, which has rendered positive results in the treatment of GVHD [125]. Additionally, the effects of using alternative sources of MSCs, such as fetal membranes [114] or UC [126], have been studied.

Some studies have analyzed systemic changes after administration of MSCs. Jitschin et al. reported that, in steroid-refractory GVHD patients after MSC infusion, a high frequency of $\mathrm{CD} 4{ }^{+} \mathrm{CD} 25^{\text {med-hi }} \mathrm{CD} 127^{\text {lo }} \mathrm{Foxp} 3^{+}$and $\mathrm{Tr} 1$ populations was detected. A decrease of Th17 cells and no changes in the number of NK or B cells were observed. Furthermore, the authors suggest an induction and maintenance of Tregs, because high levels of IL-2 were detected [42]. In another similar study an increment of $\mathrm{CD} 8^{+} \mathrm{CD} 28^{-}$and $\mathrm{CD}^{+} \mathrm{CD} 19^{+}$populations and decrease of $\mathrm{CD} 8^{+} \mathrm{CD} 28^{+}$and $\mathrm{CD}^{-} \mathrm{CD} 19^{+} \mathrm{B}$ cells after BM-MSC infusion in the responsive group were reported [127]. The first two populations of T and $\mathrm{B}$ cells are related with the maintaining of peripheral tolerance or the induction of differentiation of Tregs [127]. Similar results were obtained recently in 23 refractory
cGVHD patients treated with MSCs in which it was detected an increment in the population of $\mathrm{CD} 19^{+} \mathrm{CD} 5^{+} \mathrm{IL}-10^{+} \mathrm{B}$ cells and a high plasma concentration of IL-10 [128]. It is important to mention that it has been suggested that changes in the immune microenviroment in patients may promote the risk of infections. In this regard, a retrospective cohort study showed that treatment of GVHD with MSC is a risk factor for pneumonia related death [129]. Furthermore, Remberger and Ringdén reported treatment with MSC increment incidence of invasive fungal infections [130]. Finally, randomized Phase III trials are necessary to determine the effectiveness of MSCs in GVHD.

6.2. Autoimmune Diseases. MSC immunosuppressive capacity may be useful in the treatment of autoimmune diseases. In these pathologies, self-antigens are not tolerated, and the body mounts an immune response against its own tissues and organs. The resulting damage can be systemic (systemic lupus erythematosus) or targeted to a specific organ or tissue, such as the pancreas (type I diabetes), central nervous system (multiple sclerosis), or joints (rheumatoid arthritis) [131-133]. Animal models have demonstrated that MSC treatment is effective in some of these conditions, several of which have also been clinical trials, as described below [132, 133].

Systemic lupus erythematosus (SLE) is a chronic autoimmune disease that affects connective tissue. Clinical studies using allogeneic BM-MSCs [134] and UC-MSCs [135, 136] to treat this disease have described positive outcomes and no severe side effect. In a multicenter study, 40 SLE patients were intravenously transplanted with UC-MSCs and total or partial clinical response was observed in $60 \%$ of patients. The beneficial effect of UC-MSC administration is not permanent, because $29.2 \%$ of patients relapsed [137]. Although these results are interesting, it is important to mention that in the future a controlled and randomized study will be necessary to conclusively demonstrate the effectiveness of UCBMSC administration for SLE treatment [137]. Although the mechanism through which MSC improves patient condition is unknown, Li et al. reported increase of $\mathrm{CD} 4^{+} \mathrm{CD} 25^{+} \mathrm{Foxp}^{+}$ Tregs in peripheral blood of refractory SLE patients transplanted with UC-MSCs, even after one month of treatment. Additionally, a significant decrease of Th17 cells since the first week and up to twelve months after transplant was observed [138]. Also, Wang et al. detected an increase in IDO activity after administration of UC-MSCs in SLE patients, evidenced by kynurenine concentrations [135]. These results suggest participation of immunoregulatory mechanism regarding beneficial effects of MSC administration in such patients.

On the other hand, some reports have shown that BMMSC administration in murine model of SLE do not decrease the levels of autoantibodies or the mortality rates [139]. Furthermore, using the same animal model, Youd et al. reported that administration of allogeneic BM-MSCs to prevent or treat SLE enhances autoantibody production and even exacerbates the disease in both experimental conditions [140]. Also, a study carried out in two patients showed that administration of autologous BM-MSCs increased peripheral blood $\mathrm{CD}^{+} \mathrm{CD}_{2} 5^{+}$Foxp $^{+}$Tregs cells, but no improvement was observed in patients [43]. Today, there 
are no clinical trials in progress to assess efficacy of MSC transplantation in the treatment of Lupus erythematosus [http://www.clinicaltrials.gov/].

Type I diabetes is a chronic metabolic disease characterized by an autoimmune reaction against insulin-producing pancreatic $\beta$ cells. In vitro studies using cocktail of growth factors or genetic manipulation have shown that BM-MSCs can differentiate into insulin-producing cells [141]. However, such transdifferentiation capacity of BM-MSCs into endocrine pancreas cells in animal models has yielded contradictory results and still remains elusive. Nevertheless, in animal models have been demonstrated that MSCs can revert type I diabetes, enhances insulin secretion and sustain normoglycemia [131]. It has been proposed that such beneficial effects are mainly due to trophic factors and immunoregulators secreted by MSCs and not to their differentiation capacity [141].

In a clinical trial, the administration of insulin-producing cells derived of MSCs from adipose tissue in 11 patients reduced insulin requirements over the first 2 to 4 months after intraportal infusion [142]. In another trail, WJ-MSCs were administrated to 15 patients and a decrease in insulin requirements and blood glucose levels was observed even after 24 months of follow-up [143]. The exact mechanism of this therapeutic effect is unknown. However, it is thought that MSC immunoregulatory capacity prevents the destruction of the $\beta$-pancreatic cells rather than their differentiation capacity to regenerate $\beta$ cells. In that regard, intravenous administration of BM-MSCs in a murine model of type 1 diabetes reversed hyperglycemia and improved pancreatic regeneration, which is associated with an increase of $\mathrm{CD}^{+} \mathrm{CD} 25^{+} \mathrm{Foxp}^{+}$Tregs cells in spleen and pancreatic lymph nodes [144]. Similar results were obtained by intraperitoneal administration of MSCs from AT-MSCs in mouse models, during early development of induced type I diabetes. Increased secretion of insulin and decreased glucose levels in peripheral blood were observed but also inflammatory infiltrate in pancreatic islets. Furthermore, a low frequency of $\mathrm{CD}^{+} \mathrm{IFN} \gamma^{+}$and $\mathrm{CD} 4^{+} \mathrm{TNF} \alpha^{+}$T-cells was observed in pancreatic lymph nodes (PLNs), and in contrast, a high frequency of $\mathrm{CD} 4^{+} \mathrm{CD} 25^{+} \mathrm{Foxp}^{+}$Tregs, a decrease of IFN $\gamma$ concentration and increase in $\mathrm{TGF}_{\beta 1}$ were observed in pancreatic tissue [145].

Additionally, cotransplantation with BM-MSCs improves engraftment of pancreatic islets in humanized diabetic mouse model. Normoglycemia was maintained during 4 weeks after transplant which show that MSCs promote functionality of transplanted islets. The authors observed low infiltration by $\mathrm{CD}^{+} \mathrm{T}$ cells in the transplanted tissue and increase of $\mathrm{CD}^{+} \mathrm{CD} 25^{+} \mathrm{Foxp}^{+}$Tregs in peripheral blood [146]. Future clinical trials will be required to determine if such immunological mechanisms also occur in humans. Currently, phases I, II, and III clinical trials are evaluating the efficacy of autologous BM-MSCs [clinicaltrials.gov identifier: NCT02057211, NCT01068951, NCT01157403] and UC-MSCs in the treatment of type I diabetes [clinicaltrials.gov identifier: NCT01374854].

Two autoimmune diseases affect the central nervous system (CNS): multiple sclerosis (MS) and amyotrophic lateral sclerosis (ALS). MS is a chronic inflammatory disease characterized by the loss of myelin and axon damage. ALS selectively targets motor neurons in the brain and spinal cord. Several studies have demonstrated in murine models that MSC has positive effects for prevention and treatment of both pathologies, but it is not known what mechanisms are involved in such process. Although in vitro studies show that, in the appropriate culture medium, MSCs differentiate into cell types with neuronal and glial characteristics, contribution of such mechanisms for in vivo tissue regeneration is controversial. In contrast, in vitro and in vivo studies have suggested that immunoregulation and trophic factor secretion are the main mechanisms used by MSCs to improve the symptoms of MS and ALS $[1,147]$. Studies in a murine model with experimental autoimmune encephalomyelitis (EAE) as a model for multiple sclerosis have demonstrated that the intravenous administration of BM-MSCs improved the symptoms of the disease by decreasing central nervous system inflammation and demyelination. Other studies have reported that, in EAE mice that had received MSCs, less infiltration by $\mathrm{CD}^{+} \mathrm{T}$ cells and macrophages in CSN was observed after pathological analysis [148]. Also, it has been detected low levels of IL-17 and TNF $\alpha$ in serum [149]. Morando et al. observed that intravenous or intrathecal administration of BM-MSC promotes generation of $\mathrm{CD}^{+} \mathrm{Foxp}^{+}$in CNS and also an increase of IL17 mRNA [147]. Furthermore, after administration of hUCMSCs in a murine EAE model, the improvement of disease activity is accompanied by an increase of $\mathrm{CD} 4^{+} \mathrm{CD} 25^{+} \mathrm{Foxp} 3^{+}$ Tregs and decrease of Th17 in spleen, while in the spinal cord increased IL- 4 and IL-10 and decreased IL-1 and IL- 6 levels were observed [150]. Taken together, these results suggest that immunoregulation by MSCs has a neuroprotector effect that reduces demyelization and axonal loss and therefore results in the improvement of EAE symptoms. It is important to mention that in a recent study it was reported that BMMSCs transplanted in a murine EAE model, $\mathrm{CD}^{+}{ }^{+} \mathrm{T}$ cell infiltrate was increased in CNS, which exacerbated EAE [151]. The difference between these results could be due to disease mechanisms that underlie various models of EAE.

Similarly, allogeneic MSCs administration in murine models of experimental ALS showed an improvement in survival and motor function, in the spinal cord from MSCtreated mice [152]. Intrathecal infusion of BM-MSCs in a murine model of ALS delayed disease progression and prolonged survival [153]. Activated microglia secrete inflammatory molecules including TNF $\alpha$ and nitric oxide that play an important role in ALS and administration of hMSCs decrease microglial activation $\left(\mathrm{CD}_{11 b^{+}}\right.$cells) and concentration of TNF $\alpha$ in the spinal cord [153]. Based on the positive results obtained in murine models, clinical trials have been carried out to determine safety and efficacy of MSCs for the treatment of these pathologies. A clinical trial in which $34 \mathrm{MS}$ and ALS patients received intrathecal or intravenous autologous MSCs reported that MSC administration was safe and had an immediate immunosuppressive effect that diminished inflammation [154]. A study by Mazzini et al. studied the direct application of autologous MSCs to the spinal cord in ALS patients and reported that MSC administration generated no adverse side effects and was safe; however there was no significant improvement in patients [155]. Currently, 
no study has shown an improvement in patient's condition by MSC treatment; therefore, further clinical trials must be performed. Several of such studies, analyzing the efficacy and safety of autologous or allogeneic MSCs for the treatment of MS and ALS, are in progress [http://www.clinicaltrials.gov/].

Rheumatoid arthritis (RA) is a chronic, systemic inflammatory disorder that primarily affects joints and results in bone and cartilage destruction. Collagen-induced arthritis (CIA) initiated in susceptible strains of mice by immunization with native type II collagen serves as a model of human rheumatoid arthritis. Several authors have used this animal model to analyze MSC efficacy to improve the symptoms of this disease; however evidence remains equivocal as conflicting results have been reported. Results in this animal model suggest that inflammatory microenvironment present in RA could reverse the immunosuppressive capacity of MSCs. Djouad et al. [156] observed that MSC administration does not improve the course of disease and in vitro experiments showed that $\mathrm{TNF} \alpha$ was responsible of reverse biological function of MSCs. Additionally, it has been reported that the intravenous administration of MSCs has no effect on the progression of the disease [157] or make RA worse [158]. Similar results were reported by Papadopoulou et al. who observed immunoregulatory capacity of MSCs in vitro, but in vivo, they lost this capacity when they are administrated in the inflammatory RA environment [159]. In a recent study similar immunosuppressive capacity by synovium-derived mesenchymal stem cells (S-MSC) from AR patients and those from healthy donors was demonstrated. Both MSCs are capable of decrease proliferation of PBMC activated with PHA or alloantigens from healthy donors and also of autologous synovial T cells activated with PHA. However, when cocultures are added with exogenous IL-17 and/or $\mathrm{TNF} \alpha$, S-MSCs from AR patients or healthy donors, they lost their immunoregulatory capacity [160]. In addition, it has been reported that infusion of allogeneic-related HLA matched or partially matched MSCs does not affect RA development, while MHC mismatched MSCs exacerbate the disease activity [161].

In contrast to these results, other studies have shown that administration of syngeneic, allogeneic, or xenogeneic MSCs improves RA in mice models. Thus, González et al. showed that intraperitoneal administration of human AT-MSCs in mice with CIA reduced the incidence and severity of disease. Improvement of RA is accompanied by a decrease both in inflammation and proinflammatory cytokine secretion (IL$1 \beta$, IL-12, IL-17, TNF $\alpha$, IFN $\gamma$, etc.) and reduction in Th1 and Th17 numbers. In contrast, expansion of $\mathrm{CD} 4^{+} \mathrm{CD} 25^{+}$Foxp $3^{+}$ Tregs and IL-10 secretion was increased [162]. Similar results have been shown with human gingiva-derived mesenchymal stem cells [163]. In addition, in a RA murine model induced by antigens, intra-articular infusion of BM-MSCs prevented cartilage damage reduced the inflammation and also decreased serum concentration of TNF $\alpha$ [164].

A few studies have been done to determine safety and efficacy of MSCs administration to humans for the treatment of RA. A study carried out in four patients with refractory RA and treated with allogeneic MSCs from BM (1 patient) or UC (3 patient) administered intravenously showed no adverse effects; however clinical remissions were not detected [165]. In contrast, a clinical assay with 172 patients with active RA showed that UC-MSC administration is safe and that the improvement in patients is accompanied by an increase of $\mathrm{CD} 4{ }^{+} \mathrm{CD} 25^{+}$Foxp $^{+}$Tregs in peripheral blood and a decrease of $\mathrm{TNF} \alpha$ secretion [166]. The same authors suggest the need for large multicentre trials. In this regard, two phases I and II clinical trials are currently performed to evaluate the efficacy of UC-MSCs [clinicaltrials.gov identifier: NCT01547091 and NCT01985464].

\section{Conclusion}

BM-derived MSCs have an immunoregulatory capacity because they can regulate the function of multiple immune system components. To fulfill this role, MSCs must be activated by proinflammatory cytokines such as IFN $\gamma$. MSCs can inhibit DCs maturation and thus prevent the activation of $\mathrm{T}$ lymphocytes and even more and decrease the proliferation and cytotoxic activity of NK cells. As a result of these characteristics, MSCs are a promising alternative treatment for immune-related diseases. Currently, MSCs have been used in the treatment of autoimmune diseases, including GVHD, and have rendered positive results. Despite this encouraging debut in clinical application, it is necessary to perform more clinical trials that extend the current knowledge of the biology of MSC immunoregulatory activity to optimize and control the patient's immune response for maximum benefits. These studies will be relevant to clinical decisions in the treatment of GVHD, autoimmune diseases, and other illnesses with an immune component, such as cancer, in which MSCs play an important role in the tumor microenvironment that favors growth as our group has previously demonstrated [10].

\section{Conflict of Interests}

The authors declare that there is no conflict of interests regarding the publication of this paper.

\section{Acknowledgments}

The authors are indebted to gratefully acknowledge CONACYT (Grant no. 87183) and IMSS (Grant no. 1159) for support to Juan J. Montesinos.

\section{References}

[1] D. G. Phinney and D. J. Prockop, "Concise review: mesenchymal stem/multipotent stromal cells: the state of transdifferentiation and modes of tissue repair-current views," Stem Cells, vol. 25, no. 11, pp. 2896-2902, 2007.

[2] S. Ma, N. Xie, W. Li, B. Yuan, Y. Shi, and Y. Wang, "Immunobiology of mesenchymal stem cells," Cell Death and Differentiation, vol. 21, no. 2, pp. 216-225, 2014.

[3] D. J. Prockop and J. Youn Oh, "Mesenchymal stem/stromal cells (MSCs): role as guardians of inflammation," Molecular Therapy, vol. 20, no. 1, pp. 14-20, 2012. 
[4] A. J. Friedenstein, U. F. Deriglasova, N. N. Kulagina et al., "Precursors for fibroblasts in different populations of hematopoietic cells as detected by the in vitro colony assay method," Experimental Hematology, vol. 2, no. 2, pp. 83-92, 1974.

[5] M. F. Pittenger, A. M. Mackay, S. C. Beck et al., "Multilineage potential of adult human mesenchymal stem cells," Science, vol. 284, no. 5411, pp. 143-147, 1999.

[6] M. Dominici, K. Le Blanc, I. Mueller et al., "Minimal criteria for defining multipotent mesenchymal stromal cells. The International Society for Cellular Therapy position statement," Cytotherapy, vol. 8, no. 4, pp. 315-317, 2006.

[7] B. M. Seo, M. Miura, S. Gronthos et al., "Investigation of multipotent postnatal stem cells from human periodontal ligament," The Lancet, vol. 364, no. 9429, pp. 149-155, 2004.

[8] M. Najar, G. Raicevic, H. I. Boufker et al., "Mesenchymal stromal cells use PGE2 to modulate activation and proliferation of lymphocyte subsets: combined comparison of adipose tissue, Wharton's Jelly and bone marrow sources," Cellular Immunology, vol. 264, no. 2, pp. 171-179, 2010.

[9] J. J. Montesinos, E. Flores-Figueroa, S. Castillo-Medina et al., "Human mesenchymal stromal cells from adult and neonatal sources: Comparative analysis of their morphology, immunophenotype, differentiation patterns and neural protein expression," Cytotherapy, vol. 11, no. 2, pp. 163-176, 2009.

[10] J. J. Montesinos, M. D. L. Mora-García, H. Mayani et al., "In vitro evidence of the presence of mesenchymal stromal cells in cervical cancer and their role in protecting cancer cells from cytotoxic T cell activity," Stem Cells and Development, vol. 22, no. 18, pp. 2508-2519, 2013.

[11] E. M. Horwitz, P. L. Gordon, W. K. K. Koo et al., "Isolated allogeneic bone marrow-derived mesenchymal cells engraft and stimulate growth in children with osteogenesis imperfecta: implications for cell therapy of bone," Proceedings of the National Academy of Sciences of the United States of America, vol. 99, no. 13, pp. 8932-8937, 2002.

[12] S.-L. Chen, W.-W. Fang, F. Ye et al., "Effect on left ventricular function of intracoronary transplantation of autologous bone marrow mesenchymal stem cell in patients with acute myocardial infarction," American Journal of Cardiology, vol. 94, no. 1, pp. 92-95, 2004.

[13] R. Meisel, A. Zibert, M. Laryea, U. Göbel, W. Däubener, and D. Dilloo, "Human bone marrow stromal cells inhibit allogeneic T-cell responses by indoleamine 2,3-dioxygenasemediated tryptophan degradation," Blood, vol. 103, no. 12, pp. 4619-4621, 2004.

[14] S. Aggarwal and M. F. Pittenger, "Human mesenchymal stem cells modulate allogeneic immune cell responses," Blood, vol. 105, no. 4, pp. 1815-1822, 2005.

[15] X.-X. Jiang, Y. Zhang, B. Liu et al., "Human mesenchymal stem cells inhibit differentiation and function of monocyte-derived dendritic cells," Blood, vol. 105, no. 10, pp. 4120-4126, 2005.

[16] M. Krampera, L. Cosmi, R. Angeli et al., "Role for interferon$\gamma$ in the immunomodulatory activity of human bone marrow mesenchymal stem cells," Stem Cells, vol. 24, no. 2, pp. 386-398, 2006.

[17] J. M. Ryan, F. Barry, J. M. Murphy, and B. P. Mahon, "Interferon$\gamma$ does not break, but promotes the immunosuppressive capacity of adult human mesenchymal stem cells," Clinical \& Experimental Immunology, vol. 149, no. 2, pp. 353-363, 2007.

[18] M. Wang, D. Windgassen, and E. T. Papoutsakis, "Comparative analysis of transcriptional profiling of $\mathrm{CD}^{+}, \mathrm{CD}^{+}$and $\mathrm{CD} 8^{+}$
T cells identifies novel immune response players in T-cell activation," BMC Genomics, vol. 9, article 225, 2008.

[19] K. le Blanc, I. Rasmusson, C. Götherström et al., "Mesenchymal stem cells inhibit the expression of CD25 (interleukin-2 receptor) and CD38 on phytohaemagglutinin-activated lymphocytes," Scandinavian Journal of Immunology, vol. 60, no. 3, pp. 307-315, 2004.

[20] M. E. Groh, B. Maitra, E. Szekely, and O. N. Koç, "Human mesenchymal stem cells require monocyte-mediated activation to suppress alloreactive T cells," Experimental Hematology, vol. 33, no. 8, pp. 928-934, 2005.

[21] R. Ramasamy, C. K. Tong, H. F. Seow, S. Vidyadaran, and F. Dazzi, "The immunosuppressive effects of human bone marrow-derived mesenchymal stem cells target $\mathrm{T}$ cell proliferation but not its effector function," Cellular Immunology, vol. 251, no. 2, pp. 131-136, 2008.

[22] F. Saldanha-Araujo, R. Haddad, K. C. R. M. de Farias et al., "Mesenchymal stem cells promote the sustained expression of CD69 on activated T lymphocytes: roles of canonical and noncanonical NF- $\kappa \mathrm{B}$ signalling," Journal of Cellular and Molecular Medicine, vol. 16, no. 6, pp. 1232-1244, 2012.

[23] B. Kronsteiner, S. Wolbank, A. Peterbauer et al., "Human mesenchymal stem cells from adipose tissue and amnion influence T-cells depending on stimulation method and presence of other immune cells," Stem Cells and Development, vol. 20, no. 12, pp. 2115-2126, 2011.

[24] M. E. Castro-Manrreza, H. Mayani, A. Monroy-García et al., "Human mesenchymal stromal cells from adult and neonatal sources: a comparative in vitro analysis of their immunosuppressive properties against t cells," Stem Cells and Development, vol. 23, no. 11, pp. 1217-1232, 2014.

[25] W.-T. Hsu, C.-H. Lin, B.-L. Chiang, H.-Y. Jui, K. K.-Y. Wu, and C.-M. Lee, "Prostaglandin $\mathrm{E}_{2}$ potentiates mesenchymal stem cell-induced IL- $10^{+}$IFN- $\gamma^{+} \mathrm{CD} 4^{+}$regulatory T cells to control transplant arteriosclerosis," The Journal of Immunology, vol. 190, no. 5, pp. 2372-2380, 2013.

[26] S. Beyth, Z. Borovsky, D. Mevorach et al., "Human mesenchymal stem cells alter antigen-presenting cell maturation and induce T-cell unresponsiveness," Blood, vol. 105, no. 5, pp. 22142219, 2005.

[27] P. A. Sotiropoulou, S. A. Perez, A. D. Gritzapis, C. N. Baxevanis, and M. Papamichail, "Interactions between human mesenchymal stem cells and natural killer cells," Stem Cells, vol. 24, no. 1, pp. 74-85, 2006.

[28] Z. Selmani, A. Naji, and I. Zidi, "Human leukocyte antigenG5 secretion by human mesenchymal stem cells is required to suppress T lymphocyte and natural killer function and to induce $\mathrm{CD}^{+} \mathrm{CD} 25^{\text {high }} \mathrm{FOXP}^{+}$regulatory T cells," Stem Cells, vol. 26, no. 1, pp. 212-222, 2008.

[29] H. Sheng, Y. Wang, Y. Jin et al., "A critical role of IFN $\gamma$ in priming MSC-mediated suppression of $\mathrm{T}$ cell proliferation through up-regulation of B7-H1," Cell Research, vol. 18, no. 8, pp. 846-857, 2008.

[30] M. Giuliani, M. Fleury, A. Vernochet et al., "Long-lasting inhibitory effects of fetal liver mesenchymal stem cells on Tlymphocyte proliferation," PLOS ONE, vol. 6, no. 5, Article ID e19988, 2011.

[31] M. D. Nicola, C. Carlo-Stella, M. Magni et al., "Human bone marrow stromal cells suppress T-lymphocyte proliferation induced by cellular or nonspecific mitogenic stimuli," Blood, vol. 99, no. 10, pp. 3838-3843, 2002. 
[32] I. Rasmusson, O. Ringdén, B. Sundberg, and K. Le Blanc, "Mesenchymal stem cells inhibit lymphocyte proliferation by mitogens and alloantigens by different mechanisms," Experimental Cell Research, vol. 305, no. 1, pp. 33-41, 2005.

[33] G. Xu, L. Zhang, G. Ren et al., "Immunosuppressive properties of cloned bone marrow mesenchymal stem cells," Cell Research, vol. 17, no. 3, pp. 240-248, 2007.

[34] S. Tipnis, C. Viswanathan, and A. S. Majumdar, "Immunosuppressive properties of human umbilical cord-derived mesenchymal stem cells: role of B7-H1 and IDO," Immunology and Cell Biology, vol. 88, no. 8, pp. 795-806, 2010.

[35] S. Ghannam, J. Pène, G. Torcy-Moquet, C. Jorgensen, and H. Yssel, "Mesenchymal stem cells inhibit human Th17 cell differentiation and function and induce a $\mathrm{T}$ regulatory cell phenotype," Journal of Immunology, vol. 185, no. 1, pp. 302-312, 2010.

[36] P. Luz-Crawford, M. Kurte, J. Bravo-Alegría et al., "Mesenchymal stem cells generate a $\mathrm{CD} 4^{+} \mathrm{CD} 25^{+}$Foxp $^{+}$regulatory $\mathrm{T}$ cell population during the differentiation process of Th1 and Th17 cells," Stem Cell Research and Therapy, vol. 4, no. 3, article 65, 2013.

[37] R. Maccario, M. Podestà, A. Moretta et al., "Interaction of human mesenchymal stem cells with cells involved in alloantigen-specific immune response favors the differentiation of $\mathrm{CD}^{+} \mathrm{T}$-cell subsets expressing a regulatory/suppressive phenotype," Haematologica, vol. 90, no. 4, pp. 516-525, 2005.

[38] C. Prevosto, M. Zancolli, P. Canevali, M. R. Zocchi, and A. Poggi, "Generation of $\mathrm{CD} 4^{+}$or $\mathrm{CD}^{+}$regulatory $\mathrm{T}$ cells upon mesenchymal stem cell-lymphocyte interaction," Haematologica, vol. 92, no. 7, pp. 881-888, 2007.

[39] K. English, J. M. Ryan, L. Tobin, M. J. Murphy, F. P. Barry, and B. P. Mahon, "Cell contact, prostaglandin $\mathrm{E}_{2}$ and transforming growth factor beta 1 play non-redundant roles in human mesenchymal stem cell induction of $\mathrm{CD} 4^{+} \mathrm{CD} 25^{\mathrm{High}}$ forkhead box $\mathrm{P}^{+}$regulatory T cells," Clinical \& Experimental Immunology, vol. 156, no. 1, pp. 149-160, 2009.

[40] M. di Ianni, B. del Papa, M. de Ioanni et al., "Mesenchymal cells recruit and regulate $\mathrm{T}$ regulatory cells," Experimental Hematology, vol. 36, no. 3, pp. 309-318, 2008.

[41] H. Y. Jui, C. H. Lin, W. T. Hsu et al., "Autologous mesenchymal stem cells prevent transplant arteriosclerosis by enhancing local expression of interleukin-10, interferon- $\gamma$, and indoleamine 2,3dioxygenase," Cell Transplantation, vol. 21, no. 5, pp. 971-984, 2012.

[42] R. Jitschin, D. Mougiakakos, L. von Bahr et al., "Alterations in the cellular immune compartment of patients treated with third-party mesenchymal stromal cells following allogeneic hematopoietic stem cell transplantation," Stem Cells, vol. 31, no. 8, pp. 1715-1725, 2013.

[43] F. Carrion, E. Nova, C. Ruiz et al., "Autologous mesenchymal stem cell treatment increased T regulatory cells with no effect on disease activity in two systemic lupus erythematosus patients," Lupus, vol. 19, no. 3, pp. 317-322, 2010.

[44] N. Perico, F. Casiraghi, M. Introna et al., "Autologous mesenchymal stromal cells and kidney transplantation: a pilot study of safety and clinical feasibility," Clinical Journal of the American Society of Nephrology, vol. 6, no. 2, pp. 412-422, 2011.

[45] Y.-J. Liu, H. Kanzler, V. Soumelis, and M. Gilliet, "Dendritic cell lineage, plasticity and cross-regulation," Nature Immunology, vol. 2, no. 7, pp. 585-589, 2001.

[46] A. J. Nauta, A. B. Kruisselbrink, E. Lurvink, R. Willemze, and W. E. Fibbe, "Mesenchymal stem cells inhibit generation and function of both $\mathrm{CD} 34^{+}$-derived and monocyte-derived dendritic cells," The Journal of Immunology, vol. 177, no. 4, pp. 2080-2087, 2006.

[47] G. M. Spaggiari, H. Abdelrazik, F. Becchetti, and L. Moretta, "MSCs inhibit monocyte-derived DC maturation and function by selectively interfering with the generation of immature DCs: central role of MSC-derived prostaglandin E2," Blood, vol. 113, no. 26, pp. 6576-6583, 2009.

[48] W. Zhang, W. Ge, C. Li et al., "Effects of mesenchymal stem cells on differentiation, maturation, and function of human monocyte-derived dendritic cells," Stem Cells and Development, vol. 13, no. 3, pp. 263-271, 2004.

[49] Y.-P. Li, S. Paczesny, E. Lauret et al., "Human mesenchymal stem cells license adult $\mathrm{CD} 34^{+}$hemopoietic progenitor cells to differentiate into regulatory dendritic cells through activation of the notch pathway," The Journal of Immunology, vol. 180, no. 3, pp. 1598-1608, 2008.

[50] T. Walzer, M. Dalod, S. H. Robbins, L. Zitvogel, and E. Vivier, "Natural-killer cells and dendritic cells: "l'union fait la force"', Blood, vol. 106, no. 7, pp. 2252-2258, 2005.

[51] G. Maria Spaggiari and L. Moretta, "Cellular and molecular interactions of mesenchymal stem cells in innate immunity," Immunology and Cell Biology, vol. 91, no. 1, pp. 27-31, 2013.

[52] M. Franquesa, M. J. Hoogduijn, O. Bestard, and J. M. Grinyó, "Immunomodulatory effect of mesenchymal stem cells on B cells," Frontiers in Immunology, vol. 3, article 212, 2012.

[53] A. Corcione, F. Benvenuto, E. Ferretti et al., "Human mesenchymal stem cells modulate B-cell functions," Blood, vol. 107, no. 1, pp. 367-372, 2006.

[54] M. M. Rosado, M. E. Bernardo, M. Scarsella et al., "Inhibition of B-cell proliferation and antibody production by mesenchymal stromal cells is mediated by T cells," Stem Cells and Development, 2014.

[55] S. Tabera, J. A. Pérez-Simón, M. Díez-Campelo et al., “The effect of mesenchymal stem cells on the viability, proliferation and differentiation of B-lymphocytes," Haematologica, vol. 93, no. 9, pp. 1301-1309, 2008.

[56] P. Comoli, F. Ginevri, R. MacCario et al., "Human mesenchymal stem cells inhibit antibody production induced in vitro by allostimulation," Nephrology Dialysis Transplantation, vol. 23, no. 4, pp. 1196-1202, 2008.

[57] D. H. Munn and A. L. Mellor, "Indoleamine 2,3 dioxygenase and metabolic control of immune responses," Trends in Immunology, vol. 34, no. 3, pp. 137-143, 2013.

[58] P. Kalinski, "Regulation of immune responses by prostaglandin $\mathrm{E}_{2}$," The Journal of Immunology, vol. 188, no. 1, pp. 21-28, 2012.

[59] F. Baratelli, Y. Lin, L. Zhu et al., "Prostaglandin $\mathrm{E}_{2}$ induces FOXP3 gene expression and $\mathrm{T}$ regulatory cell function in human $\mathrm{CD}^{+}{ }^{+} \mathrm{T}$ cells," The Journal of Immunology, vol. 175, no. 3, pp. 1483-1490, 2005.

[60] M. A. Avanzini, M. E. Bernardo, A. M. Cometa et al., "Generation of mesenchymal stromal cells in the presence of platelet lysate: a phenotypic and functional comparison of umbilical cord blood- and bone marrow-derived progenitors," Haematologica, vol. 94, no. 12, pp. 1649-1660, 2009.

[61] W.-H. Liu, J.-J. Liu, J. Wu et al., "Novel mechanism of inhibition of dendritic cells maturation by mesenchymal stem cells via interleukin-10 and the JAK1/STAT3 signaling pathway," PLoS ONE, vol. 8, no. 1, Article ID e55487, 2013.

[62] S. L. Tomchuck, K. J. Zwezdaryk, S. B. Coffelt, R. S. Waterman, E. S. Danka, and A. B. Scandurro, "Toll-like receptors on 
human mesenchymal stem cells drive their migration and immunomodulating responses," Stem Cells, vol. 26, no. 1, pp. 99-107, 2008.

[63] K. English, F. P. Barry, C. P. Field-Corbett, and B. P. Mahon, "IFN- $\gamma$ and TNF- $\alpha$ differentially regulate immunomodulation by murine mesenchymal stem cells," Immunology Letters, vol. 110, no. 2, pp. 91-100, 2007.

[64] M. Najar, G. Raicevic, H. Fayyad-Kazan et al., "Bone marrow mesenchymal stromal cells induce proliferative, cytokinic and molecular changes during the $t$ cell response: the importance of the IL-10/CD210 axis," Stem Cell Reviews and Reports, 2014.

[65] Z. Yan, Y. Zhuansun, R. Chen, J. Li, and P. Ran, "Immunomodulation of mesenchymal stromal cells on regulatory T cells and its possible mechanism," Experimental Cell Research, vol. 324, no. 1, pp. 65-74, 2014.

[66] E. D. Carosella, B. Favier, N. Rouas-Freiss, P. Moreau, and J. Lemaoult, "Beyond the increasing complexity of the immunomodulatory HLA-G molecule," Blood, vol. 111, no. 10, pp. 4862-4870, 2008.

[67] R. Rizzo, D. Campioni, M. Stignani et al., "A functional role for soluble HLA-G antigens in immune modulation mediated by mesenchymal stromal cells," Cytotherapy, vol. 10, no. 4, pp. 364$375,2008$.

[68] V. L. J. L. Thijssen, F. Poirier, L. G. Baum, and A. W. Griffioen, "Galectins in the tumor endothelium: opportunities for combined cancer therapy," Blood, vol. 110, no. 8, pp. 2819-2827, 2007.

[69] T. Kadri, J.-J. Lataillade, C. Doucet et al., "Proteomic study of galectin-1 expression in human mesenchymal stem cells," Stem Cells and Development, vol. 14, no. 2, pp. 204-212, 2005.

[70] F. Gieseke, J. Böhringer, R. Bussolari, M. Dominici, R. Handgretinger, and I. Müller, "Human multipotent mesenchymal stromal cells use galectin-1 to inhibit immune effector cells," Blood, vol. 116, no. 19, pp. 3770-3779, 2010.

[71] Y. Lepelletier, S. Lecourt, A. Renand et al., "Galectin-1 and semaphorin-3A are two soluble factors conferring t-cell immunosuppression to bone marrow mesenchymal stem cell," Stem Cells and Development, vol. 19, no. 7, pp. 1075-1079, 2010.

[72] M. Sioud, A. Mobergslien, A. Boudabous, and Y. Fløisand, "Evidence for the involvement of galectin-3 in mesenchymal stem cell suppression of allogeneic T-cell proliferation," Scandinavian Journal of Immunology, vol. 71, no. 4, pp. 267-274, 2010.

[73] C. Ungerer, P. Quade-Lyssy, H. H. Radeke et al., "Galectin-9 is a suppressor of $\mathrm{T}$ and $\mathrm{B}$ cells and predicts the immune modulatory potential of mesenchymal stromal cell preparations," Stem Cells and Development, vol. 23, no. 7, pp. 755-766, 2014.

[74] F. Gieseke, A. Kruchen, N. Tzaribachev, F. Bentzien, M. Dominici, and I. Müller, "Proinflammatory stimuli induce galectin-9 in human mesenchymal stromal cells to suppress Tcell proliferation," European Journal of Immunology, vol. 43, no. 10, pp. 2741-2749, 2013.

[75] L. M. Francisco, P. T. Sage, and A. H. Sharpe, "The PD-1 pathway in tolerance and autoimmunity," Immunological Reviews, vol. 236, no. 1, pp. 219-242, 2010.

[76] C.-J. Chang, M.-L. Yen, Y.-C. Chen et al., "Placenta-derived multipotent cells exhibit immunosuppressive properties that are enhanced in the presence of interferon- $\gamma$," Stem Cells, vol. 24, no. 11, pp. 2466-2477, 2006.

[77] Z. Yan, Y. Zhuansun, G. Liu, R. Chen, J. Li, and P. Ran, "Mesenchymal stem cells suppress T cells by inducing apoptosis and through PD-1/B7-H1 interactions," Immunology Letters, vol. 162, no. 1, pp. 248-255, 2014.
[78] G. Ren, X. Zhao, L. Zhang et al., "Inflammatory cytokineinduced intercellular adhesion molecule-1 and vascular cell adhesion molecule-1 in mesenchymal stem cells are critical for immunosuppression," The Journal of Immunology, vol. 184, no. 5, pp. 2321-2328, 2010.

[79] N. K. Damle, K. Klussman, G. Leytze et al., "Costimulation of $\mathrm{T}$ lymphocytes with Lntegrin ligands intercellular adhesion molecule-1 or vascular cell adhesion molecule-1 induces functional expression of CTLA-4, a second receptor for B7," The Journal of Immunology, vol. 152, no. 6, pp. 2686-2697, 1994.

[80] L. Gatta, G. Calviello, F. Di Nicuolo et al., "Cytotoxic T lymphocyte-associated antigen-4 inhibits integrin-mediated stimulation," Immunology, vol. 107, no. 2, pp. 209-216, 2002.

[81] S. Selleri, M. M. Dieng, S. Nicoletti et al., "Cord-bloodderived mesenchymal stromal cells downmodulate $\mathrm{CD} 4^{+} \mathrm{T}$-cell activation by inducing il-10-producing th1 cells," Stem Cells and Development, vol. 22, no. 7, pp. 1063-1075, 2013.

[82] L. Chen and D. B. Flies, "Molecular mechanisms of T cell costimulation and co-inhibition," Nature Reviews Immunology, vol. 13, no. 4, pp. 227-242, 2013.

[83] T. N. Eagar, Q. Tang, M. Wolfe, Y. He, W. S. Pear, and J. A. Bluestone, "Notch 1 signaling regulates peripheral T cell activation," Immunity, vol. 20, no. 4, pp. 407-415, 2004.

[84] F. Liotta, R. Angeli, L. Cosmi et al., "Toll-like receptors 3 and 4 are expressed by human bone marrow-derived mesenchymal stem cells and can inhibit their T-cell modulatory activity by impairing notch signaling," Stem Cells, vol. 26, no. 1, pp. 279289, 2008.

[85] X. Han, Q. Yang, L. Lin et al., "Interleukin-17 enhances immunosuppression by mesenchymal stem cells," Cell Death \& Differentiation, vol. 21, no. 11, pp. 1758-1768, 2014.

[86] J. A. Ankrum, J. F. Ong, and J. M. Karp, "Mesenchymal stem cells: immune evasive, not immune privileged," Nature Biotechnology, vol. 32, no. 3, pp. 252-260, 2014.

[87] J. Cuerquis, R. Romieu-Mourez, M. François et al., "Human mesenchymal stromal cells transiently increase cytokine production by activated $\mathrm{T}$ cells before suppressing $\mathrm{T}$-cell proliferation: effect of interferon $-\gamma$ and tumor necrosis factor- $\alpha$ stimulation," Cytotherapy, vol. 16, no. 2, pp. 191-202, 2014.

[88] D. Polchert, J. Sobinsky, G. W. Douglas et al., "IFN- $\gamma$ activation of mesenchymal stem cells for treatment and prevention of graft versus host disease," European Journal of Immunology, vol. 38, no. 6, pp. 1745-1755, 2008.

[89] O. Ringdén, M. Uzunel, I. Rasmusson et al., "Mesenchymal stem cells for treatment of therapy-resistant graft-versus-host disease," Transplantation, vol. 81, no. 10, pp. 1390-1397, 2006.

[90] K. Le Blanc, F. Frassoni, L. Ball et al., "Mesenchymal stem cells for treatment of steroid-resistant, severe, acute graft-versushost disease: a phase II study," The Lancet, vol. 371, no. 9624, pp. 1579-1586, 2008.

[91] H. Ning, F. Yang, M. Jiang et al., "The correlation between cotransplantation of mesenchymal stem cells and higher recurrence rate in hematologic malignancy patients: outcome of a pilot clinical study," Leukemia, vol. 22, no. 3, pp. 593-599, 2008.

[92] B. Beutler, "Inferences, questions and possibilities in Toll-like receptor signalling," Nature, vol. 430, no. 6996, pp. 257-263, 2004.

[93] D. N. Cook, D. S. Pisetsky, and D. A. Schwartz, “Toll-like receptors in the pathogenesis of human disease," Nature Immunology, vol. 5, no. 10, pp. 975-979, 2004. 
[94] C. A. Opitz, U. M. Litzenburger, C. Lutz et al., “Toll-like receptor engagement enhances the immunosuppressive properties of human bone marrow-derived mesenchymal stem cells by inducing indoleamine-2,3-dioxygenase-1 via interferon- $\beta$ and protein kinase R," Stem Cells, vol. 27, no. 4, pp. 909-919, 2009.

[95] R. S. Waterman, S. L. Tomchuck, S. L. Henkle, and A. M. Betancourt, "A new mesenchymal stem cell (MSC) paradigm: polarization into a pro-inflammatory $\mathrm{MSC1}$ or an immunosuppressive MSC2 phenotype," PLoS ONE, vol. 5, no. 4, Article ID e10088, 2010.

[96] M. Giuliani, A. Bennaceur-Griscelli, A. Nanbakhsh et al., "TLR ligands stimulation protects MSC from NK killing," Stem Cells, vol. 32, no. 1, pp. 290-300, 2014.

[97] B. J. Jones, G. Brooke, K. Atkinson, and S. J. McTaggart, "Immunosuppression by placental indoleamine 2,3dioxygenase: a role for mesenchymal stem cells," Placenta, vol. 28, no. 11-12, pp. 1174-1181, 2007.

[98] M. Stubbendorff, T. Deuse, X. Hua et al., "Immunological properties of extraembryonic human mesenchymal stromal cells derived from gestational tissue," Stem Cells and Development, vol. 22, no. 19, pp. 2619-2629, 2013.

[99] X. Li, J. Bai, X. Ji et al., "Comprehensive characterization of four different populations of human mesenchymal stem cells as regards their immune properties, proliferation and differentiation," International Journal Molecular Medicine, vol. 34, no. 4, pp. 695-704, 2014.

[100] K. Chen, D. Wang, W. T. Du et al., "Human umbilical cord mesenchymal stem cells hUC-MSCs exert immunosuppressive activities through a $\mathrm{PGE}_{2}$-dependent mechanism," Clinical Immunology, vol. 135, no. 3, pp. 448-458, 2010.

[101] K. H. Yoo, I. K. Jang, M. W. Lee et al., "Comparison of immunomodulatory properties of mesenchymal stem cells derived from adult human tissues," Cellular Immunology, vol. 259, no. 2, pp. 150-156, 2009.

[102] A. Ribeiro, P. Laranjeira, S. Mendes et al., "Mesenchymal stem cells from umbilical cord matrix, adipose tissue and bone marrow exhibit different capability to suppress peripheral blood B, natural killer and T cells," Stem Cell Research \& Therapy, vol. 4, no. 5, article 125, 2013.

[103] M. Roemeling-van Rhijn, M. Khairoun, S. S. Korevaar et al., "Human bone marrow- and adipose tissue-derived mesenchymal stromal cells are immunosuppressive in vitro and in a humanized allograft rejection model," Journal of Stem Cell Research \& Therapy, supplement 6, article 1, Article ID 20780, 2013.

[104] S. J. Prasanna, D. Gopalakrishnan, S. R. Shankar, and A. B. Vasandan, "Pro-inflammatory cytokines, IFN $\gamma$ and $\mathrm{TNF} \alpha$, influence immune properties of human bone marrow and Wharton jelly mesenchymal stem cells differentially," PLoS ONE, vol. 5, no. 2, Article ID e9016, 2010.

[105] C. D. Li, W. Y. Zhang, H. L. Li et al., "Mesenchymal stem cells derived from human placenta suppress allogeneic umbilical cord blood lymphocyte proliferation," Cell Research, vol. 15, no. 7, pp. 539-547, 2005.

[106] P. Niemeyer, M. Kornacker, A. Mehlhorn et al., "Comparison of immunological properties of bone marrow stromal cells and adipose tissue-derived stem cells before and after osteogenic differentiation in vitro," Tissue Engineering, vol. 13, no. 1, pp. 111121, 2007.

[107] H. Fazekasova, R. Lechler, K. Langford, and G. Lombardi, "Placenta-derived MSCs are partially immunogenic and less immunomodulatory than bone marrow-derived MSCs," Journal of Tissue Engineering and Regenerative Medicine, vol. 5, no. 9, pp. 684-694, 2011.

[108] H. Karlsson, T. Erkers, S. Nava, S. Ruhm, M. Westgren, and O. Ringdén, "Stromal cells from term fetal membrane are highly suppressive in allogeneic settings in vitro," Clinical and Experimental Immunology, vol. 167, no. 3, pp. 543-555, 2012.

[109] J. M. Lee, J. Jung, H.-J. Lee et al., "Comparison of immunomodulatory effects of placenta mesenchymal stem cells with bone marrow and adipose mesenchymal stem cells," International Immunopharmacology, vol. 13, no. 2, pp. 219-224, 2012.

[110] S. Manochantr, Y. U-pratya, P. Kheolamai et al., "Immunosuppressive properties of mesenchymal stromal cells derived from amnion, placenta, Wharton's jelly and umbilical cord," Internal Medicine Journal, vol. 43, no. 4, pp. 430-439, 2013.

[111] S. M. Melief, J. J. Zwaginga, W. E. Fibbe, and H. Roelofs, "Adipose tissue-derived multipotent stromal cells have a higher immunomodulatory capacity than their bone marrow-derived counterparts," Stem Cells Translational Medicine, vol. 2, no. 6, pp. 455-463, 2013.

[112] A. I. Caplan, "Why are MSCs therapeutic? New data: new insight," Journal of Pathology, vol. 217, no. 2, pp. 318-324, 2009.

[113] D. M. Choumerianou, G. Martimianaki, E. Stiakaki, L. Kalmanti, M. Kalmanti, and H. Dimitriou, "Comparative study of stemness characteristics of mesenchymal cells from bone marrow of children and adults," Cytotherapy, vol. 12, no. 7, pp. 881-887, 2010.

[114] O. Ringdén, T. Erkers, S. Nava et al., "Fetal membrane cells for treatment of steroid-refractory acute graft-versus-host disease," Stem Cells, vol. 31, no. 3, pp. 592-601, 2013.

[115] A. Keating, "Mesenchymal stromal cells: new directions," Cell Stem Cell, vol. 10, no. 6, pp. 709-716, 2012.

[116] A. M. DiMarino, A. I. Caplan, and T. L. Bonfield, "Mesenchymal stem cells in tissue repair," Frontiers in Immunology, vol. 4, article 201, 2013.

[117] M. Sundin, O. Ringdén, B. Sundberg, S. Nava, C. Götherström, and K. Le Blanc, "No alloantibodies against mesenchymal stromal cells, but presence of anti-fetal calf serum antibodies, after transplantation in allogeneic hematopoietic stem cell recipients," Haematologica, vol. 92, no. 9, pp. 1208-1215, 2007.

[118] M. Battiwalla and P. Hematti, "Mesenchymal stem cells in hematopoietic stem cell transplantation," Cytotherapy, vol. 11, no. 5, pp. 503-515, 2009.

[119] T. Toubai, S. Paczesny, Y. Shono et al., "Mesenchymal stem cells for treatment and prevention of graft-versus-host disease after allogeneic hematopoietic cell transplantation," Current Stem Cell Research \& Therapy, vol. 4, no. 4, pp. 252-259, 2009.

[120] J. L. Ferrara, J. E. Levine, P. Reddy, and E. Holler, "Graft-versushost disease," The Lancet, vol. 373, no. 9674, pp. 1550-1561, 2009.

[121] K. Le Blanc, I. Rasmusson, B. Sundberg et al., "Treatment of severe acute graft-versus-host disease with third party haploidentical mesenchymal stem cells," The Lancet, vol. 363, no. 9419, pp. 1439-1441, 2004.

[122] M. von Bonin, F. Stölzel, A. Goedecke et al., "Treatment of refractory acute GVHD with third-party MSC expanded in platelet lysate-containing medium," Bone Marrow Transplantation, vol. 43, no. 3, pp. 245-251, 2009.

[123] I. Müller, S. Kordowich, C. Holzwarth et al., "Application of multipotent mesenchymal stromal cells in pediatric patients following allogeneic stem cell transplantation," Blood Cells, Molecules, and Diseases, vol. 40, no. 1, pp. 25-32, 2008. 
[124] L. M. Ball, M. E. Bernardo, H. Roelofs et al., "Multiple infusions of mesenchymal stromal cells induce sustained remission in children with steroid-refractory, grade III-IV acute graftversus-host disease," British Journal of Haematology, vol. 163, no. 4, pp. 501-509, 2013.

[125] V. K. Prasad, K. G. Lucas, G. I. Kleiner et al., "Efficacy and safety of ex-vivo cultured adult human mesenchymal stem cells (Prochymal (TM)) in pediatric patients with severe refractory acute graft-versus-host disease in a compassionate use study," Biology of Blood and Marrow Transplant, vol. 17, no. 4, pp. 534541, 2011.

[126] K. H. Wu, C. K. Chan, C. Tsai et al., "Effective treatment of severe steroid-resistant acute graft-versus-host disease with umbilical cord-derived mesenchymal stem cells," Transplantation, vol. 91, no. 12, pp. 1412-1416, 2011.

[127] J. Y. Weng, X. Du, S. X. Geng et al., "Mesenchymal stem cell as salvage treatment for refractory chronic GVHD," Bone Marrow Transplantation, vol. 45, no. 12, pp. 1732-1740, 2010.

[128] Y. Peng, X. Chen, Q. Liu et al., "Mesenchymal stromal cells infusions improve refractory chronic graft versus host disease through an increase of CD5+ regulatory B cells producing interleukin 10," Leukemia, 2014.

[129] U. Forslöw, O. Blennow, K. Leblanc et al., "Treatment with mesenchymal stromal cells is a risk factor for pneumonia-related death after allogeneic hematopoietic stem cell transplantation," European Journal of Haematology, vol. 89, no. 3, pp. 220-227, 2012.

[130] M. Remberger and O. Ringdén, "Treatment of severe acute graft-versus-host disease with mesenchymal stromal cells: a comparison with non-MSC treated patients," International Journal of Hematology, vol. 96, no. 6, pp. 822-824, 2012.

[131] M. Liu and Z. C. Han, "Mesenchymal stem cells: biology and clinical potential in type 1 diabetes therapy," Journal of Cellular and Molecular Medicine, vol. 12, no. 4, pp. 1155-1168, 2008.

[132] S. Ghannam, C. Bouff, F. Djouad, C. Jorgensen, and D. Noël, "Immunosuppression by mesenchymal stem cells: mechanisms and clinical applications," Stem Cell Research \& Therapy, vol. 1, no. 1, article 2, 2010.

[133] A. Dorronsoro, J. Fernández-Rueda, K. Fechter et al., "Human mesenchymal stromal cell-mediated immunoregulation: mechanisms of action and clinical applications," Bone Marrow Research, vol. 2013, Article ID 203643, 8 pages, 2013.

[134] D. Wang, H. Zhang, J. Liang et al., "Allogeneic mesenchymal stem cell transplantation in severe and refractory systemic lupus erythematosus: 4 years of experience," Cell Transplantation, vol. 22, no. 12, pp. 2267-2277, 2013.

[135] D. Wang, X. Feng, L. Lu et al., "CD8 T cell/indoleamine 2,3-dioxygenase axis is required for mesenchymal stem cell suppression of human systemic lupus erythematosus," Arthritis \& Rheumatology, vol. 66, no. 8, pp. 2234-2245, 2014.

[136] D. Wang, J. Li, Y. Zhang et al., "Umbilical cord mesenchymal stem cell transplantation in active and refractory systemic lupus erythematosus: a multicenter clinical study," Arthritis Research and Therapy, vol. 16, no. 2, article R79, 2014.

[137] T. G. Woodworth and D. E. Furst, "Safety and feasibility of umbilical cord mesenchymal stem cells in treatment-refractory systemic lupus erythematosus nephritis: time for a doubleblind placebo-controlled trial to determine efficacy," Arthritis Research and Therapy, vol. 16, no. 4, p. 113, 2014.

[138] X. Li, D. Wang, J. Liang, H. Zhang, and L. Sun, "Mesenchymal SCT ameliorates refractory cytopenia in patients with systemic lupus erythematosus," Bone Marrow Transplantation, vol. 48, no. 4, pp. 544-550, 2013.

[139] F. Schena, C. Gambini, A. Gregorio et al., "Interferon- $\gamma$ dependent inhibition of $\mathrm{B}$ cell activation by bone marrowderived mesenchymal stem cells in a murine model of systemic lupus erythematosus," Arthritis \& Rheumatism, vol. 62, no. 9, pp. 2776-2786, 2010.

[140] M. Youd, C. Blickarz, L. Woodworth et al., "Allogeneic mesenchymal stem cells do not protect NZBxNZW F1 mice from developing lupus disease," Clinical Experimental Immunology, vol. 161, no. 1, pp. 176-186, 2010.

[141] R. R. Bhonde, P. Sheshadri, S. Sharma, and A. Kumar, "Making surrogate $\beta$-cells from mesenchymal stromal cells: perspectives and future endeavors," The International Journal of Biochemistry \& Cell Biology, vol. 46, no. 1, pp. 90-102, 2014.

[142] A. V. Vanikar, S. D. Dave, U. G. Thakkar, and H. L. Trivedi, "Cotransplantation of adipose tissue-derived insulin-secreting mesenchymal stem cells and hematopoietic stem cells: a novel therapy for insulin-dependent diabetes mellitus," Stem Cells International, vol. 2010, Article ID 582382, 5 pages, 2010.

[143] J. Hu, X. Yu, Z. Wang et al., "Long term effects of the implantation of Wharton's jelly-derived mesenchymal stem cells from the umbilical cord for newly-onset type 1 diabetes mellitus," Endocrine Journal, vol. 60, no. 3, pp. 347-357, 2013.

[144] F. Ezquer, M. Ezquer, D. Contador, M. Ricca, V. Simon, and P. Conget, "The antidiabetic effect of mesenchymal stem cells is unrelated to their transdifferentiation potential but to their capability to restore Th1/Th2 balance and to modify the pancreatic microenvironment," Stem Cells, vol. 30, no. 8, pp. 1664-1674, 2012.

[145] Ê. J. Bassi, P. M. M. Moraes-Vieira, C. S. R. Moreira-Sá et al., "Immune regulatory properties of allogeneic adipose-derived mesenchymal stem cells in the treatment of experimental autoimmune diabetes," Diabetes, vol. 61, no. 10, pp. 2534-2545, 2012.

[146] H. Wu, D. Wen, and R. I. Mahato, “Third-party mesenchymal stem cells improved human islet transplantation in a humanized diabetic mouse model," Molecular Therapy, vol. 21, no. 9, pp. 1778-1786, 2013.

[147] S. Morando, T. Vigo, M. Esposito et al., "The therapeutic effect of mesenchymal stem cell transplantation in experimental autoimmune encephalomyelitis is mediated by peripheral and central mechanisms," Stem Cell Research and Therapy, vol. 3, article 3, 2012.

[148] E. Zappia, S. Casazza, E. Pedemonte et al., "Mesenchymal stem cells ameliorate experimental autoimmune encephalomyelitis inducing T-cell anergy," Blood, vol. 106, no. 5, pp. 1755-1761, 2005.

[149] M. Rafei, P. M. Campeau, A. Aguilar-Mahecha et al., "Mesenchymal stromal cells ameliorate experimental autoimmune encephalomyelitis by inhibiting CD4 Th17 $\mathrm{T}$ cells in a CC chemokine ligand 2-dependent manner," The Journal of Immunology, vol. 182, no. 10, pp. 5994-6002, 2009.

[150] R. Liu, Z. Zhang, Z. Lu et al., "Human umbilical cord stem cells ameliorate experimental autoimmune encephalomyelitis by regulating immunoinflammation and remyelination," Stem Cells and Development, vol. 22, no. 7, pp. 1053-1062, 2013.

[151] J. D. Glenn, M. D. Smith, P. A. Calabresi, and K. A. Whartenby, "Mesenchymal stem cells differentially modulate effector CD8+ $\mathrm{T}$ cell subsets and exacerbate experimental autoimmune encephalomyelitis," Stem Cells, vol. 32, no. 10, pp. 2744-2755, 2014. 
[152] A. Uccelli, M. Milanese, M. C. Principato et al., "Intravenous mesenchymal stem cells improve survival and motor function in experimental amyotrophic lateral sclerosis," Molecular Medicine, vol. 18, no. 5, pp. 794-804, 2012.

[153] C. Zhou, C. Zhang, R. Zhao, S. Chi, and P. Ge, "Human marrow stromal cells reduce microglial activation to protect motor neurons in a transgenic mouse model of amyotrophic lateral sclerosis," Journal of Neuroinflammation, vol. 10, article 52, 2013.

[154] D. Karussis, C. Karageorgiou, A. Vaknin-Dembinsky et al., "Safety and immunological effects of mesenchymal stem cell transplantation in patients with multiple sclerosis and amyotrophic lateral sclerosis," Archives of Neurology, vol. 67, no. 10, pp. 1187-1194, 2010.

[155] L. Mazzini, I. Ferrero, V. Luparello et al., "Mesenchymal stem cell transplantation in amyotrophic lateral sclerosis: a phase I clinical trial," Experimental Neurology, vol. 223, no. 1, pp. 229237, 2010.

[156] F. Djouad, V. Fritz, F. Apparailly et al., "Reversal of the immunosuppressive properties of mesenchymal stem cells by tumor necrosis factor $\alpha$ in collagen-induced arthritis," Arthritis and Rheumatism, vol. 52, no. 5, pp. 1595-1603, 2005.

[157] E. Schurgers, H. Kelchtermans, T. Mitera, L. Geboes, and P. Matthys, "Discrepancy between the in vitro and in vivo effects of murine mesenchymal stem cells on T-cell proliferation and collagen-induced arthritis," Arthritis Research and Therapy, vol. 12, article R31, 2010.

[158] B. Chen, J. Hu, L. Liao et al., "Flk-1 $1^{+}$mesenchymal stem cells aggravate collagen-induced arthritis by up-regulating interleukin-6," Clinical and Experimental Immunology, vol. 159, no. 3, pp. 292-302, 2010.

[159] A. Papadopoulou, M. Yiangou, E. Athanasiou et al., "Mesenchymal stem cells are conditionally therapeutic in preclinical models of rheumatoid arthritis," Annals of the Rheumatic Diseases, vol. 71, no. 10, pp. 1733-1740, 2012.

[160] Z. Zhang, Y. Ding, W. Li, B. Song, and R. Yang, "Interleukin$17 \mathrm{~A}$ - or tumor necrosis factor $\alpha$-mediated increase in proliferation of T cells cocultured with synovium-derived mesenchymal stem cells in rheumatoid arthritis," Arthritis Research \& Therapy, vol. 15, no. 5, article no. R169, 2013.

[161] C. Sullivan, J. M. Murphy, M. D. Griffin et al., "Genetic mismatch affects the immunosuppressive properties of mesenchymal stem cells in vitro and their ability to influence the course of collagen-induced arthritis," Arthritis Research and Therapy, vol. 14, article R167, 2012.

[162] M. A. González, E. González-Rey, L. Rico, D. Büscher, and M. Delgado, "Treatment of experimental arthritis by inducing immune tolerance with human adipose-derived mesenchymal stem cells," Arthritis \& Rheumatism, vol. 60, no. 4, pp. 1006-1019, 2009.

[163] M. Chen, W. Su, X. Lin et al., "Adoptive transfer of human gingiva-derived mesenchymal stem cells ameliorates collageninduced arthritis via suppression of Thl and Th17 cells and enhancement of regulatory T cell differentiation," Arthritis and Rheumatism, vol. 65, no. 5, pp. 1181-1193, 2013.

[164] O. Kehoe, A. Cartwright, and A. Askari, "Intra-articular injection of mesenchymal stem cells leads to reduced inflammation and cartilage damage in murine antigen-induced arthritis," Journal of Translational Medicine, vol. 12, article 157, 2014.

[165] J. Liang, X. Li, H. Zhang et al., "Allogeneic mesenchymal stem cells transplantation in patients with refractory RA," Clinical Rheumatology, vol. 31, no. 1, pp. 157-161, 2012.
[166] L. Wang, X. Cong, G. Liu et al., "Human umbilical cord mesenchymal stem cell therapy for patients with active rheumatoid arthritis: safety and efficacy," Stem Cells and Development, vol. 22, no. 24, pp. 3192-3202, 2013. 


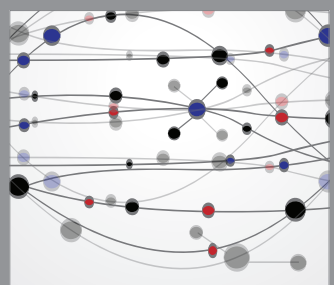

The Scientific World Journal
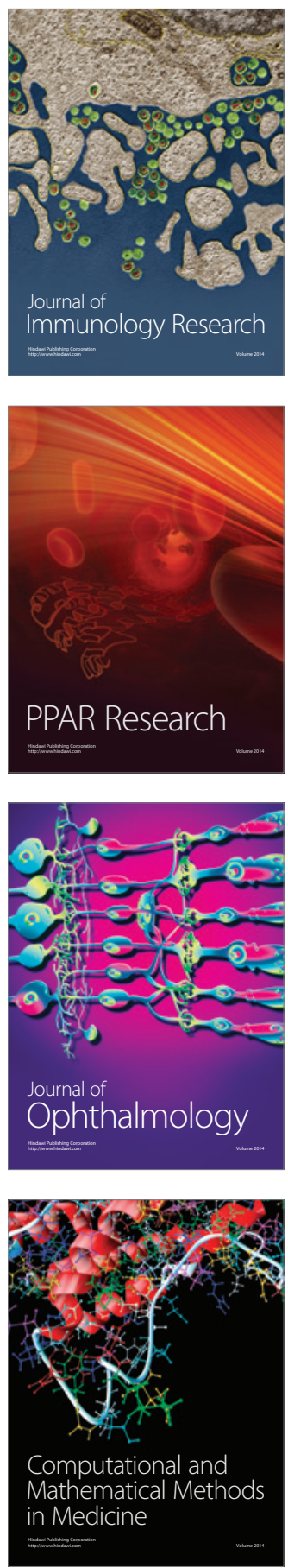

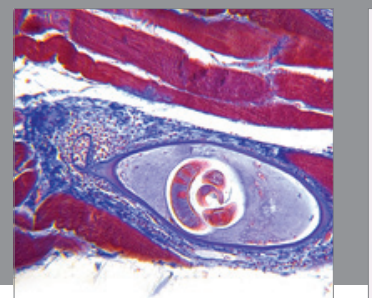

Gastroenterology

Research and Practice
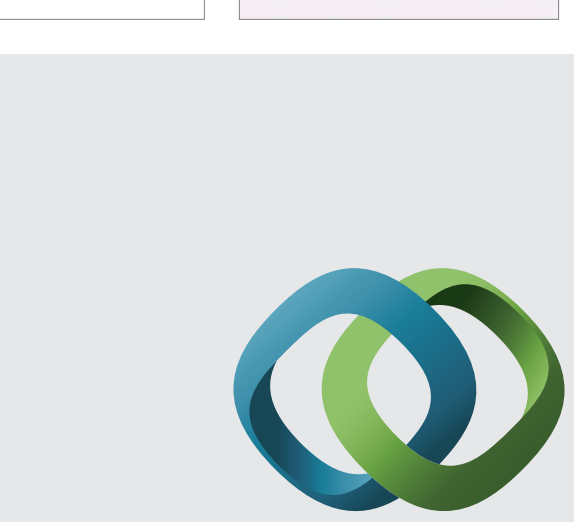

\section{Hindawi}

Submit your manuscripts at

http://www.hindawi.com
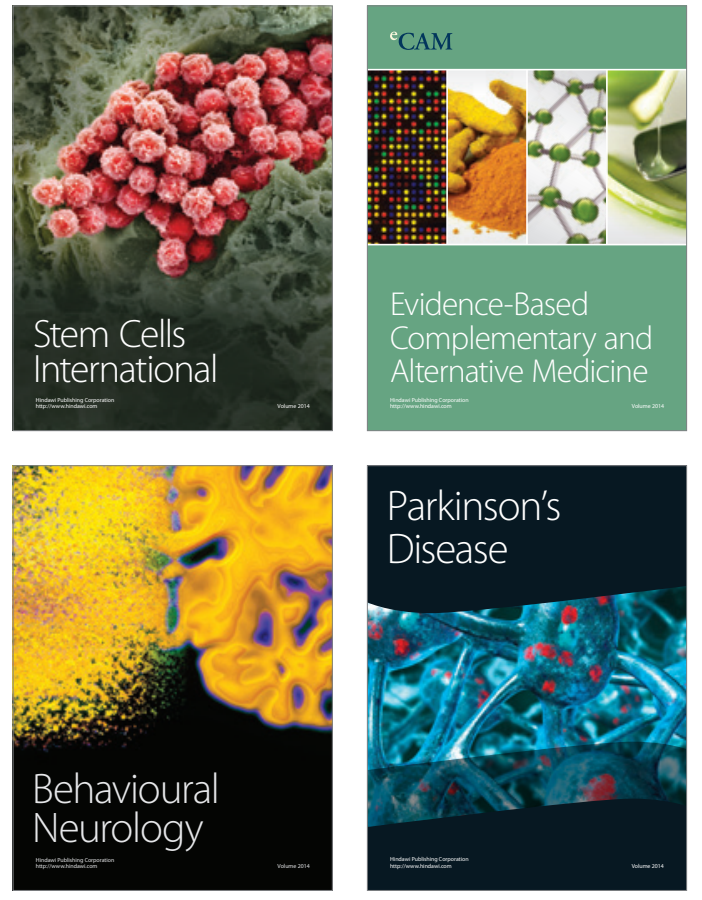
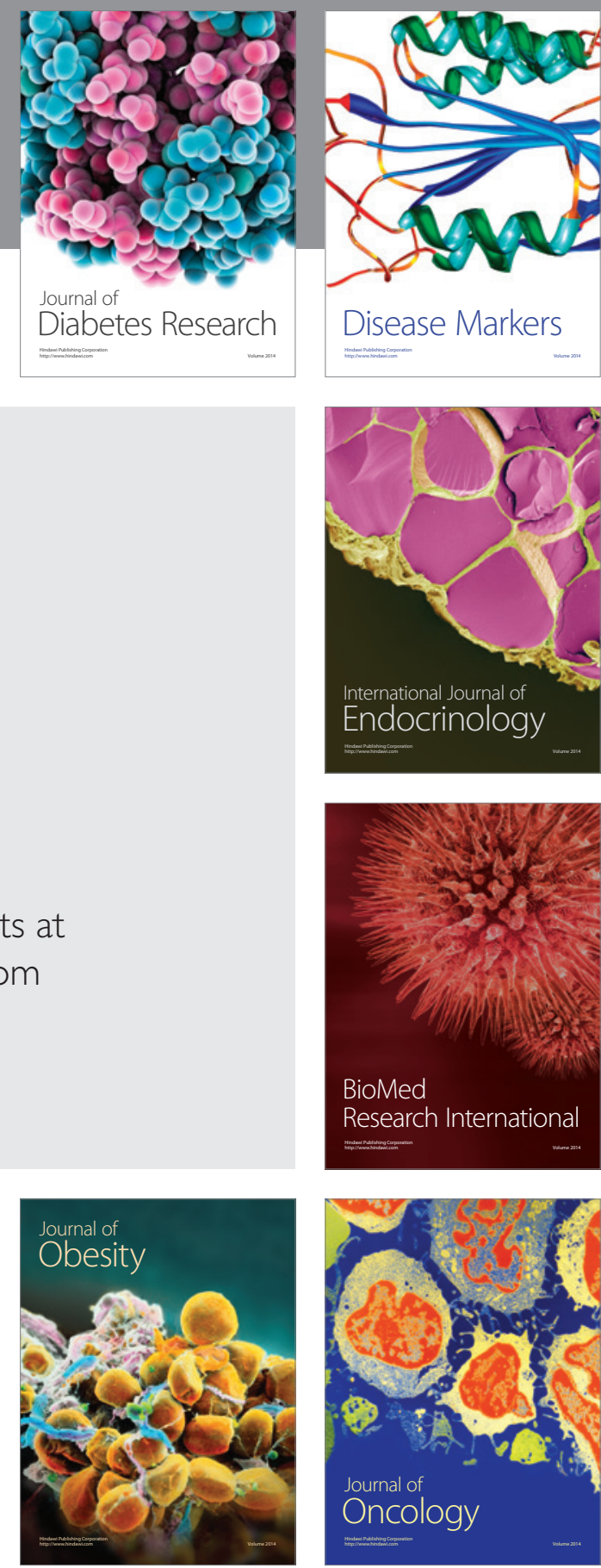

Disease Markers
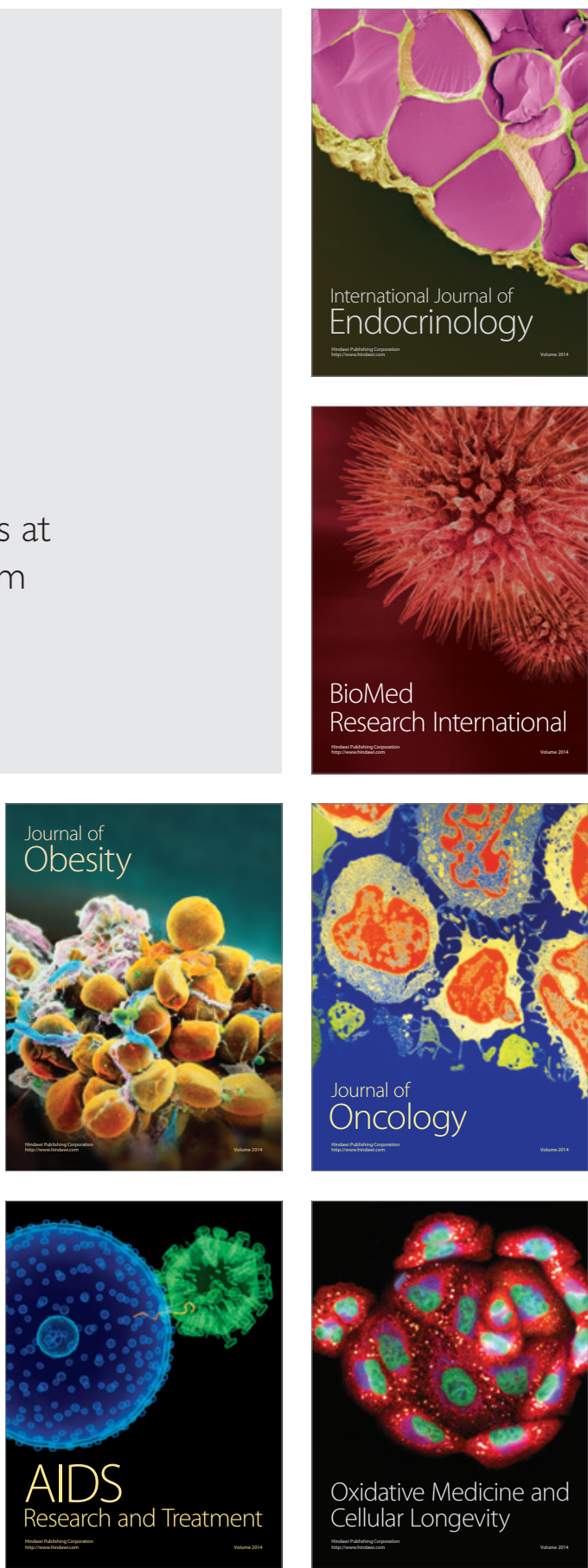